\title{
TEST DE PROPORCIONALIDAD EN EL «AGE OF BALANCING»
}

ELENA BINDI 
SUMARIO

1. PREMISA. 2. LOS NIVELES DE EQUILIBRIO. 3. IGUALDAD Y RAZONABILIDAD. 4. LA ELABORACIÓN DEL JUICIO DE PROPORCIONALIDAD EN EL MODELO ALEMÁN. 5. LA PROPORCIONALIDAD EN LA JURISPRUDENCIA DEL TRIBUNAL DE JUSTICIA DE LA UNIÓN. a) La proporcionalidad como parámetro de legitimidad de las medidas adoptadas por los Estados miembros que limitan las libertades fundamentales. b) La proporcionalidad como parámetro de validez de los actos de las instituciones de la Unión Europea: la vigilancia sobre las políticas monetarias de BCE. 6. TRIBUNAL EUROPEO DE DERECHOS HUMANOS Y JUICIO DE PROPORCIONALIDAD Y EL MARGEN DE VALORACIÓN DE LOS ESTADOS. 7. CONSIDERACIONES CONCLUSIVAS. 


\title{
TEST DE PROPORCIONALIDAD EN EL «AGE OF BALANCING»*
}

\author{
ELENA BINDI** \\ Profesora asociada confirmada de Instituciones de derecho público en la \\ Universidad de Siena
}

\section{PREMISA}

Como es sabido, las constituciones de la segunda posguerra en la Europa occidental nacieron en un momento de categórica toma de posición contra el pasado y un intento de cambiar el presente, o al menos de indicar el camino para un nuevo modelo social. Fueron manifestaciones de una pluralidad de partes que ya no reflejaban más el Estado monoclase de la época liberal, puesto que un tejido social complejo, caracterizado por un fuerte pluralismo y por impulsos antagonistas habían sustituido el aspecto compacto de la sociedad burguesa. Por lo tanto, las constituciones de la segunda posguerra no podían ignorar las condiciones de vida de las clases más desfavorecidas y debían abrirse a la sociedad para tratar de sentar las bases que mejoraran las condiciones de vida de los sujetos débiles ${ }^{1}$.

* Traducción del italiano de la doctora Maria Eugenia Granata.

** Professore Associato de Instituciones de Derecho Público de la Universidad de Siena. Dipartimento di Giurisprudenza. Via Mattioli, 10. 53100 Siena - Italia. Correo electrónico: elena. bindi@unisi.it

${ }^{1}$ Sobre la estrecha relación que existe entre el cambio social y el nacimiento de nuevos derechos, véase N. BobBio, L'età dei diritti, Torino 1990, págs. 67 ss. 
Se abrió camino la toma de conciencia de que no era suficiente garantizar las llamadas libertades clásicas, típicas de los Estados liberales, como por ejemplo la libertad personal, de domicilio, de circulación y de residencia, si no se las acompañaba por los llamados derechos sociales (derecho a la instrucción, derecho a la asistencia sanitaria, derecho a la previsión y asistencia social), porque para «conseguir que los derechos de libertad fuesen efectivos» se necesitaba «garantizar a los individuos un mínimo de bienes materiales» sin los cuales no habrían podido «poner en práctica su libertad»; «si el individuo, por motivos de carácter material» no hubiera estado en «condiciones de ejercer efectivamente la propia libertad», entonces ésta habría tenido «solamente un valor formal», habría quedado «solo en papeles» ${ }^{2}$. A la conciencia de que se necesitaba reafirmar la universalidad de los derechos fundamentales y establecer un punto de referencia jurídico fuerte que se opusiera a las razones de la política (teniendo los constituyentes de los países de Europa occidental aún nítidos en su mente los horrores del exterminio nazi), se unió por lo tanto la conciencia de que las libertades del pasado se habrían hecho concretas solamente si se unían a los derechos sociales, los únicos instrumentos que hubieran podido lograr que fueran efectivas para toda la población.

A decir verdad, los derechos sociales ya se habían previsto en algunas cartas magnas entre finales del setecientos y la primera mitad del ochocientos ${ }^{3}$, pero hasta la Constitución de Weimar de 1919 los derechos sociales no encontraron amplia formulación en un texto constitucional.

El debate que tuvo lugar después de la aprobación de este último texto, fue testigo de cómo se dividió la doctrina con relación a la eficacia jurídica que se debía reconocer a dichos derechos, a pesar de que todas las opiniones doctrinarias negasen que se tratara de derechos con acción directa frente a la autoridad judicial. Por un lado se encontraban quienes consideraban dichas disposiciones meras directivas, que el legislador podía dar eficacia o no discre-

2 P. HäBerle, I diritti fondamentali nello stato costituzionale (1983), trad. it. a cargo de P. Ridola, Nis, Roma, 1993, págs. 49 y 50.

${ }^{3}$ Los derechos sociales ya se habían presentado en la constitución revolucionaria francesa de 1793 , dictada por los jacobinos, donde se podían entrever ya algunas referencias explícitas a la socialdemocracia. Esta necesidad de reconocer el derecho de cada individuo a un mínimo de servicios en su lucha contra la pobreza, la ignorancia, el desempleo, la enfermedad, ya aparecida durante la Revolución francesa, nos la encontramos definida con mayor precisión en la Constitución francesa de 1848 y en la Constitución de la República romana de 1849. 
cionalmente, por el otro quienes consideraban vinculantes las citadas disposiciones para el legislador ordinario y jurídicamente relevantes a los fines de la interpretación de la ley ${ }^{4}$.

También en Italia el debate suscitado en la Asamblea constituyente sobre las técnicas de formulación de los derechos fundamentales se vio suficientemente influenciado por la experiencia anterior a la Constitución de Weimar. Aún entre los que consideraban las citadas disposiciones vinculantes para el legislador ordinario había quienes temían que su falta de efectividad determinara una «descalificación» de la normatividad de toda la Carta Magna. No obstante esto, prevaleció la voluntad de introducir en el texto constitucional no solo las libertades clásicas, sino también los derechos sociales.

Después de todo, en el momento de la fundación de un nuevo ordenamiento social, expresión del Estado pluriclase, no podían no agregarse a la Constitución esas normas programáticas necesarias para sentar las bases de la «revolución social pacífica» para combatir con las armas del derecho. Habría recaído luego sobre el legislador la obligación de dar efectividad a la parte programática escrita en la Constitución, cuya flexibilidad y ductilidad habría garantizado la adaptación a los cambios sociales 5 .

La Constitución italiana (CI), como por otra parte las otras Constituciones de la segunda posguerra de la Europa continental, tenía la ambición de mirar al futuro, de tener suficiente previsión, de abrirse a los cambios inevitables, difíciles de entrever pero no de imaginar. Y para preservar el texto constitucional de previsibles ataques de las mayorías políticas que vendrían a continuación en el gobierno del país, la elección se inclinó por la rigidez del texto mismo, con la previsión de un procedimiento agravado por su modificación (art. 138 CI): los altos quorum requeridos para proceder a la revisión parecían, de hecho, poner un límite sólido a la llamada tiranía de la mayoría. De este modo la Constitución, expresión de valores compartidos por las diferentes fuerzas políticas, pero sobre todo fruto del acuerdo de los partidos antifascistas, se prevenía ante reformas que desearan solamente la mayoría política de turno. De igual manera, la introducción

${ }^{4}$ Véase A. Baldassarre, Diritti sociali, en Enc. giur., XI, Treccani, Roma 1989, págs. 3 ss.

5 Sobre la génesis y el desarrollo de los derechos sociales, cfr. M. LuCiani, Positività, metapositività e parapositività dei diritti fondamentali, en AA. VV., Studi in onore di Lorenza Carlassare, a cargo de G. Brunelli, A. Pugiotto, P. Veronesi, Napoli, Edizioni Scientifiche Italiane, 2009, vol. III, págs. 1060 ss.; P. CARETTI, I diritti sociali. Libertà e diritti fondamentali, Torino, Giappichelli, 2002, págs. 22 ss.; S. Della VAlle, «I diritti umani e i diritti del cittadino europeo», en Diritto Pubblico, 2001, págs. 983 ss.; B. PEzzINI, La decisione sui diritti sociali. Indagine sulla struttura costituzionale dei diritti sociali, Milano, Giuffrè, 2001. 
de instancias de control de constitucionalidad de las leyes apuntaba a asegurar la plena conformidad de las decisiones legislativas a los valores constitucionales ${ }^{6}$.

Como es sabido, es diferente el origen del Convenio Europeo de Derechos Humanos $(\mathrm{CEDH})$, que nació en defensa de las libertades clásicas de la tradición liberal occidental, puestas a dura prueba por los totalitarismos de la primera mitad del Novecientos; el Convenio no surge como expresión del Estado social de derecho. Solo a manera de ejemplo, en el CEDH (art. 1 Prot. 1) no se menciona la «función social» del derecho de propiedad y, más en general, no existen referencias a los derechos sociales ${ }^{7}$. No obstante, esa falta de previsión de la función social no impidió al Tribunal de Estrasburgo la posibilidad de considerar legítimos los límites al derecho de propiedad justificados por exigencias de justicia social.

También el humus en el cual se desarrolló la tutela de los derechos fundamentales en el ámbito de la UE parece verse afectado por sus propios orígenes: un ordenamiento en el cual las disposiciones que conciernen a los derechos de las personas eran, de todos modos, funcionales respecto a los objetivos esencialmente económicos ${ }^{8}$. Sin embargo la exigencia de tutela de los derechos humanos a nivel comunitario se hizo sentir mucho antes del momento de la redacción de la Carta de Niza, en 2002, a pesar de que los Tratados constitutivos de las Comunidades europeas en la versión original no contuviesen disposiciones específicas sobre la cuestión. El surgimiento de una tutela de los derechos fundamentales a nivel comunitario estaba estrechamente relacionado con el fenómeno de la expansión natural de las competencias y era funcional con respecto a los objetivos esencialmente económicos de los Tratados, cuyo silencio de origen en materia de derechos fue colmado progresivamente ya sea por el Tribunal de Justicia en forma "pretoria» ${ }^{9}$

${ }^{6}$ Sobre la justiciabilidad de los derechos fundamentales, la literatura es muy amplia; véase, entre muchos otros, con la bibliografía allí citada, G. PALOMBella, L'autorità dei diritti. I diritti fondamentali tra istituzioni e norme, Bari, 2002, págs. 26 ss.

7 A. GUAZZAROTTI, «Interpretazione conforme alla Cedu e proporzionalità e adeguatezza: il diritto di proprietà», en AA. VV., Interpretazione conforme e tecniche argomenative, a cargo de M. D'Amico y B. Randazzo, Cuadernos del «Gruppo di Pisa», Torino, Giappichelli, 2009, págs. 161 ss.; F. Tulkens, La Cour européenne des droits de l'homme: le chemin parcouru, les defies de demain, Cabiers de Droit, 2012, págs. 422 ss.

8 R. BIN, L'interpretazione conforme. Due o tre cose che so di lei, ponencia al Congreso, L'interpretazione conforme al diritto Ue. Profili e limiti di un vincolo problematico, Rovigo, 15-16 de mayo de 2014.

9 Como es sabido, en una primera fase la Corte constitucional italiana se negó a tener en cuenta los derechos humanos: cfr. la jurisprudencia citada por U. VILLANI, «I diritti fondamentali tra Carta di Nizza Convenzione europea dei diritti dell'uomo e progetto di Costituzione europea», en Il Diritto dell'Unione Europea, 2004, fasc. 1, 73-74. 
(a partir de las sentencias Stauder ${ }^{10}$ y $N_{o l d}{ }^{11}$ ), ya sea por diferentes textos comunitarios.

Esta diferencia de origen no puede no reflejarse en las evaluaciones llevadas a cabo por los diferentes Tribunales (Tribunales constitucionales, Tribunal Europeo de Derechos Humanos y Tribunal de Justicia de la UE) acerca de la prevalencia de un interés sobre otro, en caso de conflicto entre normas, si bien la evolución jurisprudencial ha puesto de manifiesto cómo se produjo una indudable «contaminación» entre diferentes ordenamientos.

\section{LOS NIVELES DE EQUILIBRIO}

La redacción de las Cartas sobre todo por principios, caracterizados por circunstancias abiertas y heterogéneas $^{12}$ (principios que no están en permanente

${ }^{10}$ El punto de partida es la muy conocida sentencia Stauder (sent. 12 novembre 1969, 29/69, Stauder c. Stadt Ulm, in Foro it., 1970, IV, col. 204 ss., cursivas añadidas): en esta sentencia, el Tribunal de Justicia ha declarado que la protección de los derechos fundamentales forma parte integrante de los principios generales del Derecho comunitario y que, por tanto, la protección de esos derechos debe ser garantizada por el propio Tribunal de Justicia en el marco de los objetivos y la estructura de la Comunidad Europea: cfr., sobre el punto, F. Cocozza, Diritto comune delle libertà in Europa, Torino, 1994, págs. 132 ss.; M. CARTABIA, Principi inviolabili e integrazione europea, Milano, Giuffré, 1995, págs. 21 ss.; A. Pizzorusso, Il patrimonio costituzionale europeo, Bologna, Il Mulino, 2002, págs. 18 ss., 25 ss.; J. H. H. WeILER, The Constitution of Europe. «Do the New Clothes Have an Emperor?» and Other Essays on European Integration, Cambridge University Press, Cambridge, 2003; P. Costanzo, «Il riconoscimento e la tutela dei diritti fondamentali», en P. Costanzo - L. MezzetTi - A. Ruggeri (a cargo de), Lineamenti di diritto costituzionale dell'Unione europea, Torino, Giappichelli, 2008, págs. 357 ss.; V. SciarabBa, Tra fonti e Corti. Diritti e principi fondamentali in Europa: profili costituzionali e comparati degli sviluppi sovranazionali, Padova, Cedam, 2008, págs. 83 ss.; D. ButTuRINI, La tutela dei diritti fondamentali nell'ordinamento costituzionale italiano ed europeo, Napoli, Edizioni Scientifiche Italiane, 2009, págs. 1 ss.; M. Nicolini, El «nivel integral» de tutela como contenido de los derechos fundamentales europeos, en Revista de Derecho Político, septiembre-diciembre 2012, págs. 317 ss.

${ }_{11}$ Pero es sobre todo con la sentencia Nold con la que establece expresamente que «los derechos fundamentales forman parte integrante de los principios generales del Derecho comunitario del cual el primero garantiza el cumplimiento. El Tribunal de Justicia para garantizar la protección de los derechos, se ve obligado a inspirarse en las tradiciones constitucionales comunes a los Estados miembros y no podía, por lo tanto, admitir medidas incompatibles con los derechos reconocidos y garantizados por las constituciones de los Estados»: sent. 14 mayo 1974, Nold, en Foro it., 1974, IV, col. 296 ss.

${ }^{12}$ Sobre la formulación de los principios, cfr. E. BINDI, La giurisprudenza costituzionale in materia di buon andamento della giustizia, en Giur. cost., 1996, págs. 2758 ss. y la doctrina allí referenciada. 
conflicto entre ellos, pero sí necesitan ser armonizados) hace que sea ineludible el recurso a las técnicas de equilibrio, en lo que se refiere a su ejecución y realización, mediante límites recíprocos.

Equilibrar los derechos significa comparar normas constitucionales que contemplan derechos en conflicto, para aceptar, dentro de un sistema normativo, qué derechos deben prevalecer - y en qué medida - sobre otros.

Esta operación se desprende como lógica consecuencia de la cuestión de que ningún derecho es ilimitado y tampoco lo son los derechos fundamentales definidos como inviolables en la Constitución. El ejercicio de un derecho está limitado por el ejercicio de otro derecho, porque, como afirmó la misma Corte constitucional italiana en su primera sentencia (la núm. 1 de 1956) «en el ámbito del ordenamiento las diferentes esferas jurídicas deben por necesidad limitarse recíprocamente, para que puedan coexistir en la ordenada convivencia social».

En consecuencia, los derechos deben ajustarse recíprocamente y pueden ser diferentes los niveles de equilibrio, en particular los que derivan de las actividades desarrolladas ya sea por el legislador o por los jueces.

Las características de los principios constitucionales como normas de contenido amplio e indeterminado, a veces unidas a previsiones limitativas del derecho como «orden público», «buenas costumbres», «seguridad», de contenido igualmente vago, requieren ante todo una intervención para su implementación por parte del legislador.

Los órganos del circuito representativo, persiguiendo las finalidades de la propia orientación política, preceden a la composición y armonización de los principios constitucionales, realizando un primer ajuste.

Las operaciones de equilibrio deben cumplir algunos pasos necesarios. Antes que nada, el equilibrio debe efectuarse solo entre derechos que poseen el mismo rango constitucional. En segundo lugar, en el ámbito de dos derechos del mismo rango, un derecho puede sucumbir en la operación de equilibrio solo de forma razonable y proporcionada.

Por último y de todos modos, el sacrificio de un derecho no puede comprimir lo que se denomina el «contenido mínimo» del derecho, porque se pondría en contraste con la previsión constitucional del derecho sacrificado, que también tiene rango constitucional y no puede menoscabar su núcleo intangible. Como subraya la Corte constitucional italiana en la sentencia sobre el caso ILVA (sent. núm. 85 de 2013):

«Todos los derechos fundamentales tutelados por la Constitución se encuentran en relación de integración recíproca y no es posible por lo tanto, individualizar uno de ellos que tenga el predominio absoluto sobre los otros. La 
tutela debe ser siempre sistémica y no fraccionada en una serie de normas sin coordinación y en conflicto potencial entre ellas» (sentencia nro. 264 de 2012). Si así no fuera, se verificaría la expansión ilimitada de uno de los derechos que se convertiría en «tirano» con relación a otras situaciones jurídicas constitucionalmente reconocidas y protegidas, que constituyen, en su conjunto, expresión de la dignidad de la persona. $\left[\ldots . . »^{13}\right.$.

Pero más allá del nivel legislativo, el equilibrio lo realiza también el juez ordinario. En su actividad de interpretación de un enunciado legislativo conforme a uno o más enunciados constitucionales, so pena de inadmisibilidad de la cuestión de legitimidad constitucional, los jueces a menudo están llamados a llevar a cabo un ajuste directo de los principios en conflicto, con el fin de valorar entre otras cosas la juridicidad de la Constitución ${ }^{14}$.

Si el camino de la interpretación, si bien obligatoriamente efectuado, no conduce a un resultado adecuado, no queda otro remedio que solicitar la intervención de la Corte constitucional.

Es aquí cuando se llama a los Tribunales a «evaluar» el equilibrio entre principios, llevado a cabo por el legislador a través de una norma legislativa y es ésta la sede de elaboración del control de razonabilidad y en particular el test de proporcionalidad, técnicas ya consolidadas y utilizadas para evitar invadir la zona reservada a las decisiones discrecionales del legislador ${ }^{15}$.

Si la operación de equilibrio no ha sido cumplida correctamente por este último, el Tribunal constitucional deberá proceder a equilibrar nueva y correctamente los derechos constitucionalmente tutelados, y a declarar por lo tanto ilegítima la norma sometida a su control.

La técnica de equilibrio de los derechos utiliza categorías generales que otorgan a los jueces constitucionales una amplia discrecionalidad. Racionalidad y proporcionalidad, contenido mínimo del derecho, constituyen conceptos ampliamente flexibles que permiten al Tribunal Constitucional «mediar» entre normas constitucionales que tienen estructuras y finalidades diferentes.

Hasta se ha llegado a hablar de una edad del equilibrio (age of balancing) como una amenaza para la tutela de los derechos ${ }^{16}$. La aplicación sistemática de con-

13 Corte constitucional italiana, sent. núm. 85 de 2013, cfr. el punto 9 de los Considerandos.

14 Véase Corte constitucional italiana, sent. núm. 356 de 1996.

15 Sobre las estrategias argumentativas elaboradas por la Corte constitucional italiana cfr. T. Groppi - I. SPIGno, Constitutional reasoning in the Italian Constitutional Court, en Rivista Aic, n. 4/2014, 21 de noviembre de 2014.

${ }^{16}$ Como recuerda G. PINo, Proporzionalità, diritti, democrazia, en Diritto e società, 2014, fasc. 3 , pág. 7, nt. 25 la feliz frase «age of balancing» fue acuñada por T. A. AleinikofF, Constitutional Law in the Age of Balancing, en Yale Law Journal, 1987, vol. 96, págs. 943 ss.; cfr. también G. WeBBer, 
troles por parte de los Tribunales sobre el equilibrio realizado por el legislador ha suscitado muchos temores sobre la posibilidad de que «la edad del equilibrio» tenga la fuerza de borrar «la edad de los derechos» ${ }^{17}$. Pero es la misma estructura de los derechos fundamentales la que requiere un equilibrio por parte del legislador y sobre esta operación de equilibrio debe pronunciarse la Corte constitucional utilizando técnicas de argumentación como el test de proporcionalidad. Justamente para evitar que los derechos se compriman infinitamente, los Tribunales — no solo el Tribunal constitucional alemán y la Corte constitucional italiana, sino también el Tribunal Europeo de Derechos Humanos y el Tribunal de Justicia de la Unión Europea- han elaborado técnicas para controlar que haya una zona de intangibilidad interna en el mismo derecho, salvaguardada de otros ajustes: la zona del núcleo esencial, cuyo derecho se sacrificaría irremediablemente en el caso en que fuera afectada ${ }^{18}$.

Claramente, cuando el equilibrio se ha realizado ya a nivel constitucional o bien cuando los textos constitucionales ya han individualizado principios supremos (el llamado núcleo duro «salvaguardado» de la revisión constitucional: sent. 1146 de 1988 de la Corte constitucional italiana), ni el legislador ordinario ni la Corte constitucional podrán ignorarlo a la hora de realizar el equilibrio que les corresponde. Si bien la misma Corte constitucional parece reevaluar la jerarquía entre principios presentes en la Constitución cuando afirma, volviendo al

«Proportionality, Balancing, and the Cult of Constitutional Rights Scholarship», en Canadian Journal of Law E Jurisprudence, 2010, vol. 23, págs.179 ss.

${ }_{17}$ Se han expresado miedos por parte de A. PACE, Diritti «fondamentali» al di là della Costituzione?, cit.; Id., Metodi interpretativi e costituzionalismo, en Quaderni costituzionali, 1, 2001, 35-62; L. FerrajoLI, «Costituzionalismo principialista e costituzionalismo garantista», en Giur. cost., 3, 2010, 28092811.; G. WebBer, The Negotiable Constitution. On the Limitation of Rights, Cambridge, Cambridge U. P., 2009; Id., Proportionality, Balancing, and the Cult of Constitutional Rights Scholarship, cit.; A. SCHIAVELLO, «La fine dell'età dei diritti», in Etica E Politica, XV, 2013, 1, 120-145; S. TsaKYRAKIS, «Proportionality: An Assault on Human Rights?», in $I \bullet C O N$ International Journal of Constitutional Law, vol. 7, 3, 2009, págs. 468 ss.; B. ÇALI, «Balancing Human Rights? Methodological Problems with Weights, Scales and Proportions», in Human Rights Quarterly, vol. 29, 2007, 251-270; L. HeNKIN, «Infallibility Under Law: Constitutional Balancing», in Columbia Law Review, vol. 78, 1978, 1048; P. McFadden, «The Balancing Test», in Boston College Law Review, vol. 29, 1988, 641-642.

18 También debido a que puede experimentar la hipótesis extrema de conflicto entre dos núcleos esenciales y en este caso la función del Tribunal constitucional es intentar, en la obra de ajuste, el mejor equilibrio a fin de no sacrificar a uno sin posibilidad de reparación. Cuando uno de ellos permanece irremediablemente sacrificado, la doctrina habla de «caso trágico»: cfr. M. ATIENZA, «On The Reasonable in Law», in Ratio Juris, 1990, vol. 3, 154-155; ID., Las razones del Derecho. Teorías de la argumentación jurídica, Madrid, Centro de Estudios Constitucionales, 1991, 251-252; Id., «Los límites de la interpretación constitucional. De nuevo sobre los casos trágicos», en Isonomía, 1997, 6, 7-30; J. BomHOFF, L. ZucCA, The Tragedy of Ms Evans: Conflicts and Incommensurability of Rights, cit. 
caso ILVA, que: «La Constitución italiana, como las otras constituciones democráticas y pluralistas contemporáneas, requiere un continuo y recíproco equilibrio entre principios y derechos fundamentales, sin pretensiones de absolutismo para ninguno de ellos. La calificación de «primarios» de los valores del ambiente y de la salud significa por lo tanto que los mismos no pueden sacrificarse por otros intereses, aun cuando estén tutelados constitucionalmente, que no se los ubique en la cima de un orden jerárquico absoluto. El punto de equilibrio, justamente porque es dinámico y no predeterminado anteriormente, debe considerarse - por parte del legislador cuando dicta la ley o del juez de las leyes durante el control - según criterios de proporcionalidad y razonabilidad, tales que no permitan un sacrificio de su núcleo esencial» (sent. núm. 85 de 2013) ${ }^{19}$.

\section{IGUALDAD Y RAZONABILIDAD}

El principio de razonabilidad no se presenta explícitamente en la Constitución italiana, es decir no está previsto formalmente en una disposición constitucional; su fundamento normativo emerge de la Corte constitucional italiana a través de la aplicación del principio de igualdad.

Desde comienzos de los años sesenta, la Corte afrontó, en efecto, de forma directa, el problema de su competencia para controlar las diferencias legislativas ajenas al ámbito de aplicación meramente literal del primer inciso del art. $3^{20} \mathrm{y}$ se atribuyó el control sobre los motivos adoptados por el legislador para justificar un trato diferente a situaciones aparentemente iguales, declarando que «el principio de igualdad se viola también cuando la ley, sin un motivo razonable, trata de forma diferente a ciudadanos que se encuentran en situaciones iguales» (sent. núm. 15 de $\left.1960^{21}\right)$. Con la afirmación de la necesidad de evaluar las razones que justifiquen una determinada elección legislativa, el control de razonabilidad entró en la jurisprudencia constitucional e inevitablemente terminó ampliando los poderes de la Corte, llevándola hacia el control del mérito de las decisiones políticas

${ }^{19}$ Corte constitucional italiana, sent. núm. 85 de 2013, cfr. el punto 9 de los Considerandos, cit. Se expresan en tal sentido Tribunal de Justicia de la UE, sent. 13 de diciembre de 1979, causa 44/79, Liselotte Hauer c. Land Rheinland-Pfalz; y TEDH, sent. 17 de octubre de 1986, Rees v. Reino Unido; sent. 18 de diciembre de 1987, F. v. Sueza.

${ }^{20}$ En años anteriores, el principio de igualdad todavía no había demostrado sus capacidades de aplicación, debido a que la Corte constitucional italiana había dado una interpretación restrictiva, negándose a evaluar las diferenciaciones establecidas por la ley a menos que expresamente encluidas en la lista del primer párrafo del art. 3 de la Constitución (sent. núm. 28 del 1957): tenían que ser diferenciaciones de «raza, idioma, sexo, opiniones políticas o religiosas».

${ }^{21}$ Cursivas añadidas. 
legislativas, a pesar de que la ley excluya «cualquier control sobre el uso del poder discrecional del Congreso» (art. 28 de la Ley núm. 87 de 1953).

Desde los primeros años de actividad, la Corte constitucional italiana, a la hora de evaluar la razonabilidad de los motivos que fundamentaban las soluciones adoptadas por el legislador, caminaba sobre un campo minado, porque corría el riesgo de ejercer un control no ya de legitimidad constitucional sino mucho más cercano a un control de mérito de las decisiones legislativas.

Por lo tanto, para evitar desvíos hacia el ámbito legislativo, ámbito reservado al Parlamento, se admitió el juicio de razonabilidad solo cuando estuviera acompañado por el principio de igualdad, y a través de esta indisoluble unión se individualizó en la Carta magna un freno a las posibles invasiones de la Corte en el ámbito de las decisiones legislativas. Del principio de igualdad se desprendía la prohibición de leyes irracionales, por lo cual la Corte debía limitarse a evaluar si la norma impugnada presentaba discriminaciones arbitrarias entre situaciones homogéneas o bien asimilaciones arbitrarias entre situaciones diferentes. Para poder aplicarse el art. 3 CI se necesitaba un término de confrontación (el llamado tertium comparationis) sobre la base del cual poder evaluar si la diferencia actuada por el legislador era razonable o arbitraria. Dicho de otra manera, el recurso al criterio de razonabilidad requería siempre la referencia al art. $3 \mathrm{CI}$, aplicando este último a través de un esquema «ternario»: 1) norma de ley impugnada; 2) art. 3 CI como parámetro constitucional invocado 3) norma de confrontación o bien tertium comparationis normativo homogéneo a la norma impugnada, con base en la cual evaluar esta última (sent. núm. 10 de 1980; 15 y 277 de 1983) ${ }^{22}$.

De este modo, el juez constitucional sí está legitimado para incidir en el área reservada al legislador, pero solo de forma marginal, porque justamente el recurso al art. 3 como parámetro constitucional aplicado mediante el esquema ternario obliga de todos modos a la Corte a confrontar normas legislativas y encierra de este modo su juicio dentro de elecciones políticas llevadas a cabo por el legislador, atenuando el riesgo de invasión del ámbito de la discrecionalidad legislativa.

22 A modo de ejemplo, la Corte constitucional italiana que tenía que evaluar si eran regulaciones razonables que operaban diferentes tratamientos entre los ciudadanos, compara la posición de algunos sujetos regulada por la disposición impugnada con la posición de otras entidades reguladas por otra disposición (tertium comparationis), y después de comprobar la homogeneidad de las posiciones comparadas, constató la diferencia de trato sin justificación razonable y, por tanto, declaró inconstitucional la regulación impugnada por violación del principio de igualdad, con lo que ella estableció la misma disciplina legislativa para las posiciones en comparación, «a través de la igualdad de la posición adoptada como discriminatoria» a la que se solicitó la aplicación (sent. núm. 220 de 1982). 


\section{LA ELABORACIÓN DEL JUICIO DE PROPORCIONALIDAD DEL MODELO ALEMÁN}

La Corte constitucional italiana no se conformaba con limitarse a controlar «las marcas de frontera» (Sandulli) ${ }^{23}$ y comenzó a aplicar el criterio de razonabilidad, desvinculado del modelo tripartito ex art. $3 \mathrm{CI}$, sobre todo gracias a la aplicación del art. $97 \mathrm{CI}$ sobre la base del buen funcionamiento, y del art. $24 \mathrm{CI}$ sobre la base del derecho de defensa, parámetros flexibles, no susceptibles de enunciación precisa. El control de razonabilidad, unido a otros parámetros constitucionales que no fueran el art. 3, permitió en efecto, la elaboración y la definición de un esquema binario, esquema que se funda en la confrontación directa entre norma constitucional y norma ordinaria, para lo cual ya no había un juicio comparativo donde el término de comparación (tertium comparationis) permitiera acoger la ruptura del ordenamiento. La Corte pone de manifiesto la contradicción entre norma ordinaria y parámetro constitucional a través de la aplicación del principio (criterio) de razonabilidad, o sea evaluando, sobre la base del parámetro constitucional, si subsisten o no razones justificativas de la elección legislativa adoptada en la norma de rango ordinario. En particular, la Corte implementó juicios de idoneidad de la elección legislativa adoptada respecto al fin constitucionalmente impuesto, a los cuales se agregan los juicios de congruencia, que se ajustan a la contradictoriedad intrinseca (con base en las cuales se examinan las normas impugnadas en relación con el sistema normativo de todo el sector); y finalmente el recurso a los juicios de proporcionalidad (o de equilibrio) elaborados sobre todo en materia de derechos fundamentales, como el derecho de defensa, juicios mediante los cuales la Corte mide (o dice hacerlo) el sacrificio que una situación constitucionalmente garantizada padece para que se asegure la tutela de otro interés competente ${ }^{24}$.

La Corte constitucional italiana representa el juicio de razonabilidad a través de figuras sintomáticas de vicio de legitimidad constitucional como la idoneidad, la congruencia o la proporcionalidad.

En particular, el principio de proporcionalidad se considera un corolario del principio de razonabilidad (es decir una especificación de un principio más

23 A. M. SANDulli, Il principio di ragionevolezza nella giurisprudenza costituzionale, en Dir. soc, 1975, págs. 569 ss.; muy crítico acerca de la aplicabilidad del criterio de razonabilidad en la interpretación judicial A. PACE, Diritti «fondamentali» al di là della Costituzione?, en Politica del diritto, 1993, 1, págs. 3 ss.

${ }^{24}$ De acuerdo con la clasificación propuesta en la doctrina por R. Tosi, Spunti per una riflessione sui criteri di ragionevolezza nella giurisprudenza costituzionale, en Giur. cost. 1993, págs. 552 ss. 
amplio como el de razonabilidad ${ }^{25}$ ) y —cómo este último— también está implícito en el ordenamiento italiano ${ }^{26}$. Su contenido "puede identificarse con la exigencia de que cualquier límite al ejercicio de un derecho fundamental se justifique gracias a la exigencia de tutelar un interés u otro derecho, y se produzca de la manera menos invasiva posible» ${ }^{27}$.

Al poner en práctica el principio de proporcionalidad, así como el más amplio principio de razonabilidad, la Corte puede recurrir a la técnica argumentativa del juicio de proporcionalidad, como se ha elaborado en el ordenamiento alemán ${ }^{28}$. La argumentación, a través del test de proporcionalidad en la jurisprudencia del Tribunal constitucional alemán, ya consolidada sobre este punto, se articula en tres momentos ${ }^{29}$ : a) idoneidad de los medios elegidos con relación al

${ }^{25}$ Cfr. P. J. G. Kapteyn- P. VerLoren van Themaat, Introductions to the Law of the European Communities After the Coming Into Force of th Single European Act, London 1989, pág. 144. Sobre la definición del criterio de proporcionalidad en la ponderación entre derechos fundamentales, cfr. F. Rosa, «Limiti ai diritti e clausole orizzontali: Canada, Nuova Zelanda, Israele e Sudafrica a confronto», en Dir. pubbl. comp. eur., n. 4, 2002, págs. 633 ss.

26 Por ejemplo, como establece la Corte constitucional italiana en la sentencia núm. 220 de 1995, el «principio de la proporción [.... es una expresión directa de la razonabilidad (ex art. 3 $\mathrm{CI}) »$; cfr. A. Morrone, «Corte costituzionale e principio generale di ragionevolezza», en A. CERrI (a cargo de), La ragionevolezza nella ricerca scientifica ed il suo ruolo specifico nel sapere giuridico, Roma, Aracne, 2007, págs. 239 ss.

27 Así G. Pino, Proporzionalità, diritti, democrazia, cit., donde se distingue entre «test de proporcionalidad» $\mathrm{y}$ «principio de proporcionalidad». «El test de proporcionalidad es un procedimiento argumentativo (conocido en sus tres o cuatro pasos: legalidad, idoneidad, necesidad, proporcionalidad en sentido estricto o el equilibrio), que se descompone y regula las diversas evaluaciones que se pueden tomar en el examen de la admisibilidad de una injerencia en un derecho fundamental, por una medida pública que tiene la intención de perseguir un interés público o para proteger otro derecho fundamental. El principio de proporcionalidad es más bien, de hecho, un principio, que es - como todos los principios - una disposición que se caracteriza por un alto grado de generalidad, de indeterminación [.... El El principio de proporcionalidad, por lo tanto, justifica el uso del test de proporcionalidad, pero no se identifica con él. Es decir: el test de proporcionalidad es una manera, aunque no la única, de poner en práctica el principio de proporcionalidad».

${ }^{28}$ D. Kommers, The Constitutional Jurisprudence of the Federal Republic of Germany, Durham, Duke University Press, 1997, pág. 46; A. BARAK, Proportionality: Constitutional Rights and their Limitations, Cambridge, Cambridge University Press, New York, 2012, págs. 175 ss., espec. págs. 181 ss. Sobre el pensamiento de Barak cfr. S. PenNicino, Contributo allo studio della ragionevolezza nel diritto comparato, Maggioli, Bologna, 2012, págs. 53 s. Acerca del juicio de proporcionalidad en el ordenamiento alemán cfr. también N. VICECONTE, «Proporzionalità e bilanciamento d'interessi nelle decisioni delle Corti», en G. Azzariti (a cargo de), Interpretazione costituzionale, Giappichelli, Torino, 2007, pág. 192; D. RÉAume, Limitations on Constitutional Rights: The Logic of Proportionality, Oxford Legal Studies Research Paper No. 26/2009.

29 En la doctrina otros distinguen cuatro momentos. En particular D. SCHEFOLD, «Aspetti di ragionevolezza nella giurisprudenza costituzionale tedesca», en AA. VV., Il principio di 
fin perseguido por el legislador; b) necesidad de que el medio elegido sea lo más contenido posible; c) proporcionalidad entre sacrificio impuesto y ventaja conseguida $^{30}$.

La Corte constitucional italiana utilizó el test de proporcionalidad según el modelo alemán cuando afrontó la espinosa cuestión de la ley electoral núm. 270 de 2005. Tratándose de una cuestión delicada quiso estructurar el juicio de proporcionalidad en las tres fases típicas del modelo alemán, mientras que en la jurisprudencia anterior el juicio de proporcionalidad tendía a confundirse con el juicio de razonabilidad. Debido a la complejidad del asunto se sintió en la obligación, no solo de estructurar el propio juicio sino también de relacionarlo con el anterior, como la sentencia núm. 1130 del 1988 ${ }^{31}$, indicándolo (erróneamente) como el primer caso de aplicación del test de proporcionalidad. En la sentencia núm. 1130 de 1988, en efecto, la Corte se limitó a una evaluación de las los

ragionevolezza nella giurisprudenza della Corte costituzionale, cit., 128 - aludido también por A. A. Cervati, In tema di interpretazione della Costituzione, nuove tecniche argomentative e «bilanciamento» tra valori costituzionali (a proposito di alcune riflessioni della dottrina austriaca e tedesca), ivi, 83, nt. 42, distingue los siguientes momentos: a) el propósito de la intervención debe ser legítimo constitucionalmente y sobre todo no arbitrario; b) la intervención legislativa debe ser idónea, apropiada para perseguir el propósito predefinido; c) tal intervención debe ser necesaria; d) finalmente siempre la mencionada intervención debe ser proporcional en sentido propio, o bien tolerable.

30 Tres pasos, porque algunos autores no incluyen el paso relativo a la legitimidad de la finalidad perseguida por el legislador: cfr. C. STARCK, «I diritti fondamentali nel Grundgesetz della Repubblica federale tedesca», en Giur. cost., 1992, pág. 2529; R. Alexy, Teoria dei diritti fondamentali (1986), Bologna, il Mulino, 2012, pág. 133; ID., «The Construction of Constitutional Rights», in Law E Ethics of Human Rights, 2010, vol. 4, 1, pág. 24; J. RIVERs, «A Theory of Constitutional Rights and the British Constitution», en R. AleXY (a cargo de), A Theory of Constitutional Rights, Oxford, Oxford U. P., 2002, XXXI-XXXII; J. J. Moreso, Ways of Solving Conflicts of Constitutional Rights: Proportionalism and Specificationism, in Ratio Juris, 2012, vol. 25, fasc. 1, pág. 36; cfr. además J. LuTHER, Ragionevolezza e Verbältinismäßigkeit nella giurisprudenza costituzionale tedesca, en Dir. soc., 1993, pág. 456. Sin embargo, no debe olvidarse que el juicio de proporcionalidad ha asumido, en la jurisprudencia constitucional alemana, un papel esencial en materia de derechos fundamentales. Por lo demás como recuerda A. CERRI, voz Ragionevolezza delle leggi, cit., 13, en un sistema gradualista como el alemán, el juicio de proporcionalidad se hace más necesario en los niveles más elevados de la escala de valores.

31 En este caso, la Corte constitucional italiana se ha pronunciado, en referencia al art. 97 de la Constitución italiana, sobre el cuestionamiento de constitucionalidad de dos leyes regionales de Lombardía, concernientes a las contribuciones para el financiamiento de grupos colegiados del consejo y a la asignación de personal para estos últimos. La Corte ha declarado no fundada la cuestión, porque no parece poco razonable dotar a los grupos colegiados de medios financieros más consistentes y poner a disposición de los mismos, personal más numeroso a fin de permitir a éstos perseguir de mejor manera las múltiples tareas vinculadas al correcto funcionamiento del consejo regional. 
elementos internos de la norma impugnada, con base en la cual se comprobó solamente la idoneidad de los medios elegidos respecto al fin perseguido (utilizando solamente el primer paso empleado por el Tribunal constitucional alemán en la aplicación del principio de proporcionalidad y renunciando de esta forma a cualquier análisis de costes-beneficios) ${ }^{32}$.

Vale la pena recordar que dicha evaluación la había llevado a cabo el juez constitucional en muchos casos anteriores a la sentencia núm. 1130 de $1988^{33}$.

En la sentencia núm. 1 de 2014 en cambio, articuló el juicio en las tres fases típicas del juicio de proporcionalidad.

En primer lugar, desde el punto de vista de la congruencia del medio en relación al fin, los jueces constitucionales reconocieron que la finalidad de asegurar la estabilidad del ejecutivo puede ser perseguida a través de un premio de mayoría. Subsiste, por ello, una conexión racional entre el medio predispuesto (premio de mayoría) y el fin perseguido (garantizar la estabilidad del gobierno), pero falta sin embargo una conexión racional con relación al fin contenido en el modelo electoral proporcional (asegurar la representatividad en la asamblea parlamentaria) $)^{34}$.

La norma impugnada, en efecto, urdió la atribución del premio, alterando la ratio del modelo electoral elegido. El «premio de mayoría» excesivo, unido a la «previsión de una barrera legal mínima de acceso» altera el nivel de distorsión del voto constitucionalmente tolerable en un sistema electoral de tipo proporcional, determinando «una excesiva separación entre la composición del órgano de representación política, que está en el centro del sistema de democracia representativa y de la forma de gobierno parlamentaria prevista por la Constitución y la voluntad de los ciudadanos expresada a través del voto, que constituye el instrumento principal de manifestación de soberanía popular» ${ }^{35}$.

32 Utilizando de tal modo los juicios de idoneidad. Si acaso podría sostenerse que la Corte haya recurrido a los juicios de congruencia que conciernen a la contradictoriedad intrínseca. Lo que es cierto en todo caso es que la Corte constitucional italiana no recurrió al juicio de proporcionalidad, al menos a la luz de la tipología aquí acogida.

33 Cfr. R. Tosi, cit., pág. 560; al respecto cfr., también, S. BARTOLE, Gruppi consiliari e buon andamento dell'amministrazione, en Le regioni, 1989, pág. 1826, cui adde Tosi.

${ }^{34}$ Sobre el premio de mayoría, cfr. M. OliveTti, La reforma elctoral italiana de 2015, en Cuadernos de pensamiento político, FAES, Madrid, julio 2015, págs. 35 ss., espec. págs. 44 ss. Además, P. A. САРотовті, Riforme costituzionali, riforme elettorali e governabilità. La riforma elettorale, Bagno a Ripoli, 2007, pág. 172; M. VolPI - M. Oliviero, Sistemi elettorali e democrazie, Giappichelli, Torino, 2007; L. TruCCO, «Premio di maggioranza e premi di maggioranza: l'“incaglio" regionale», en le Regioni, 2013, pág. 89.

35 Así el punto 3.1 de los Considerandos de la sent. núm. 1 de 2014, cit. En conclusión, la Corte constitucional italiana no ha dicho que el único sistema costituzionalmente compatible sea 
La Corte constitucional italiana, en este caso, siguiendo los pasos del Tribunal constitucional alemán ${ }^{36}$, lleva a cabo una operación de equilibrio a través de la cual mide el sacrificio que una situación constitucionalmente garantizada padece para que se pueda asegurar la tutela de otro interés competente ${ }^{37}$.

Las normas censuradas, aunque persigan un objetivo de relevancia constitucional como es el de la estabilidad del gobierno del país y la eficacia de los procesos de decisión en el ámbito parlamentario, dictaminan una disciplina que no respeta el

el sistema proporcional: Sobre la inconsistencia de la «vulgata», que ha sido difundida al amparo de la reiterada senencia. n. 1 del 2014, según la cual «la Corte habría considerado el sistema proporcional como el único constitucionalmente compatible» véase al entonces Presidente de la Corte constitucional, Gaetano Silvestri, que estuvo atento para aclarar que una tal «vulgata» no estaría «autorizada por el texto de la sentencia» (vid. «Relazione sulla giurisprudenza costituzionale del 2013» del 27 febrero 2014, 6; y, posteriormente, en la entrevista a cargo de D. TEgA, La Corte costituzionale vista da vicino, en Quaderni costituzionali, 2014, págs. $760 \mathrm{~s}$.

${ }^{36}$ Como subraya S. BARTOLE (L'elaborazione del parametro e del protocollo delle argomentazioni, en AA. VV., Corte costituzionale e principio di eguaglianza, Padua, Cedam, 2001, págs. 35 ss.), es muy importante que la Corte constitucional italiana ponga mucha atención y cuidado en la definición de estándares de juicio; así también M. CARTABIA, I principi di ragionevolezza e proporzionalità nella giurisprudenza costituzionale italiana, Conferencia trilateral de las Cortes constitucionales italiana, portuguesa y española, Roma, Palazzo della Consulta 24-26 de octubre 2013, en cortecostituzionale.it, $5 \mathrm{~s}$. del paper. Además, con referencia a la influencia ejercida por la jurisprudencia constitucional alemana sobre la sentencia núm. 1 de 2014, véase G. SiLvestri, Considerazioni introduttive alla III sessione del XVI Congresso delle Corti costituzionali europee, Viena, 13 de mayo de 2014, en Cortecostituzionale.it. Para un análisis de la sentencia núm. 1 de 2014 con perspectiva comparada, con particular atención a la jurisprudencia de la Supreme Court of U. S. y del Bundesverfassungsgericht alemán cfr. MARTINUZZI, La fine di un antico feticcio: la sindacabilità della legge elettorale italiana, en Forumcostituzionale.it, 30 de mayo de 2014. Sobre el recurso a la comparación en la jurisprudencia constitucional italiana T. GROPPI, «Bottom up globalization? Il ricorso a precedenti stranieri da parte delle Corti costituzionali», en Quaderni costituzionali, 2011, págs. 199 ss. y la bibliografía allí citada. Muestra dudas sobre el recurso a la comparación por así decir implícita como expresión de verdadera comparación G. De VergotTini, Oltre il dialogo tra corti, Bologna, Il Mulino, 2010, págs. 143 ss. Acerca de los peligros ínsitos en recurrir al método comparativo, aludiendo a los precedentes extranjeros en modo fragmentado y extrapolándolos del contexto cfr. T. Groppi- M. C. Ponthoreau (a cargo de), The Use of Foreign Precedents by Constitutional Judges, Oxford, Hart Publishing, 2013, en particular Conclusion. The Use of Foreign Precedents by Constitutional Judges. A Limited Practice, An Uncertain Future, págs. 411 ss., espec. pág. 429.

37 Sobre el balance entre el interés de la gobernabilidad y el de la representación cfr. las observaciones de G. Azzariti, La sentenza e gli effetti indiretti sulla legislazione futura, en Nomos, n. 3/2013, 2 ss.; A. Pertici, La Corte costituzionale dichiara l'incostituzionalità della legge elettorale tra attese e sorprese (con qualche indicazione per il legislatore), en Forumcostituzionale.it, 4 de febrero de 2014; G. Demuro, La sostenibilità del premio di maggioranza, en confronticostituzionali.eu, 31 de enero de 2014; A. PISANESCHI, Giustizia costituzionale e leggi elettorali: le ragioni di un controllo diffcile, en Quaderni costituzionali, 2014; N. VIzIOLI, Possibili conseguenze della sentenza Corte cost. 1/2014 sulla legge elettorale per il Parlamento europeo e sul disegno di legge n. 1385, en Ianus.it, 2014, fasc. 10 
vinculo del menor sacrificio posible de los otros intereses y valores constitucionalmente protegidos, creando un contraste con los arts. 1, inciso 2; 3; 48 inciso 2 y $67 \mathrm{CI}$ En definitiva, dicha disciplina no es proporcional al objetivo perseguido, puesto que determina una comprensión de la función representativa de la asamblea, y del mismo derecho de voto, excesiva y tal que produce una alteración profunda en la composición de la representación democrática, sobre la cual se funda toda la arquitectura del ordenamiento constitucional vigente.

De este modo, la normativa en examen no supera el test de proporcionalidad en sentido estricto.

En cambio, con referencia al sistema electoral del Senado, la Corte utiliza el test de proporcionalidad en sentido estricto, apoyándose en el de la congruencia.

Del tenor literal de la motivación, se deduce sin embargo que la Corte considera el test de congruencia una articulación interna del juicio de proporcionalidad sobre lo elaborado por la jurisprudencia del Tribunal constitucional alemán. «En este caso, — aclara la Corte — el test de proporcionalidad evidencia, además del defecto de proporcionalidad en sentido estricto de la disciplina censurada, la idoneidad de la misma para alcanzar el objetivo perseguido, de modo más neto respecto a la disciplina prevista para la elección de la Cámara de Diputados. Está, de hecho, estableciendo que la atribución del premio de mayoría se basa en una escala regional, produce el efecto que la mayoría en la asamblea del Senado sea el resultado casual de una suma de premios regionales, que puede terminar por invertir el resultado obtenido de las listas o coaliciones de listas de base nacional, favoreciendo la formación de mayorías parlamentarias no coincidentes en los dos ramos del Parlamento, incluso en presencia de una distribución del voto en el conjunto sustancialmente homogéneo [...]

En definitiva, corre el riesgo de frustrar el resultado que se trata de conseguir con una adecuada estabilidad de la mayoría parlamentaria y del gobierno» ${ }^{38}$ : aquí el medio (premio de mayoría en escala regional) no es congruente respecto al fin de la estabilidad del ejecutivo.

La Corte por lo tanto, ha utilizado el juicio de proporcionalidad articulado en tres fases sobre el modelo alemán, tal y como ha hecho en la sent. n. 162 del 2014, en el tema de la fecundación heteróloga. En esta declaración, ha procedido a aplicar el test de proporcionalidad y ha verificado que las normativas examinadas no respetasen el vínculo del menor sacrificio posible que una situación constitucionalmente garantizada pueda sufrir para que se asegure una tutela a otro interés contendiente.

${ }^{38}$ Así el punto 4 de los Considerandos, de la sent. n. 1 del 2014, cit. 
En la sentencia n. 1130 del 1988, en cambio, se había detenido en la fase de la valoración de la congruencia del medio predispuesto por el legislador al fin perseguido, y quizás si no hubiera omitido la fase de la valoración de la proporcionalidad en sentido estricto, el resultado podría haber sido diferente, de aceptación en lugar que de rechazo ${ }^{39}$.

\section{LA PROPORCIONALIDAD EN LA JURISPRUDENCIA DEL TRIBUNAL DE JUSTICIA DE LA UNIÓN EUROPEA}

El modelo alemán de juicio de proporcionalidad, por otro lado, ha tenido amplia difusión en muchos Estados de Europa occidental incluso gracias a la obra realizada por el Tribunal de Justicia de la Unión Europea. Como es sabido, el nivel de convergencia de los ordenamientos es fruto de la circularidad de los modelos, que desde el derecho interno de los Estados miembros contribuyen a la elaboración de las tradiciones constitucionales comunes, que después recaen desde el nivel comunitario al nivel interno. El ordenamiento alemán ha desempeñado sin dudas, un rol determinante en el desarrollo del principio de proporcionalidad $^{40}$, elevándolo al nivel del Derecho de la Unión Europea para después introducirse como una cascada en el Derecho de diferentes Estados miembros. El principio de proporcionalidad se ha transmitido, por lo tanto, desde el ordenamiento nacional alemán (gracias al instrumento de la cuestión prejudicial) hacia el derecho comunitario, para después recaer sobre un número creciente de

39 Acerca del hecho de que la Corte constitucional italiana se detiene en muchos casos en la etapa del juicio de congruencia, cfr. R. BIN, Ragionevolezza e divisione dei poteri, en A. LA TORRE - A. Spadaro, La ragionevolezza nel diritto, Giappichelli, Torino, 2002, págs. 59 ss., espec. págs. 65 y ss. donde se lee: «En cuanto al juicio de congruencia del medio legislativo respecto al fin, me parece que esta forma de "razonabilidad», o tal vez más exactamente de racionalidad, no tiene una autonomía específica, sino que es parte inseparable de los otros dos. Es seguramente un segmento del juicio de igualdad (la ley que es «irracional» no puede justificadamente discriminar las situaciones), y es seguramente un segmento del juicio de reequilibrio (si la ley no logra potenciar el interés que quisiera promover, ciertamente no puede justificarse el hecho de que dañe el interés antagónico). Por ello frecuentemente el juicio de la Corte constitucional se detiene en esta primera etapa, sin necesidad de proceder a otras» (cursivas en el texto).

40 Véase J. Ziller, «Sviluppi nel diritto amministrativo europeo», en Riv. It. Dir. Pubbl. Com., 1998, pág. 592; A. SANDUlli, La proporzionalità dell'azione amministrativa, Padova, Cedam, 1998, passim; M. P. CHITI, Il mediatore europeo, cit., pág. 323; D. U. GALETTA, «Il diritto ad una buona amministrazione europea», en Riv. Ital. Dir. Pubbl. Com., 2005, págs. 851 ss. Sobre el juicio de proporcionalidad, que salió a la luz inicialmente en el campo del derecho administrativo prusiano, cfr. A. Barak, Proportionality, Cambridge University Press, 2012, págs. 175-210. 
ordenamientos nacionales, según un fenómeno llamado de «spill over» ${ }^{41}$, o de fecundación recíproca y de «radiación» (rayonnement), como otros lo prefieren llamar, visto que la expresión normalmente utilizada de «spill over» evoca la idea de un líquido que escapa de un contenedor demasiado 1 leno ${ }^{42}$.

El principio de proporcionalidad, presente en el derecho comunitario a través del derecho alemán, ha asumido un rol limitante al ejercicio del poder normativo de las instituciones europeas y de los Estados miembros, volviéndose un parámetro de legitimidad de los actos comunitarios y de las leyes y actos nacionales ${ }^{43}$. El juicio de proporcionalidad en el ordenamiento de la Unión Europea ha sido, por lo tanto, utilizado tanto para evaluar la legitimidad de las medidas adoptadas por los Estados miembros limitativas de las libertades fundamentales, como un parámetro de validez de los actos de la Unión. En estos casos, sobre el modelo alemán, la legitimidad tanto de las leyes nacionales como de los actos de la Unión está subordinada a la condición de que el acto sea idóneo y necesario para el logro de los objetivos legítimamente perseguidos, y que, entre varias opciones posibles, haya sido preferida aquella menos limitativa y que no constituya respecto al propósito buscado una intervención tan desproporcionada e inaceptable que dañe la sustancia misma de los derechos tutelados ${ }^{44}$.

La jurisprudencia al respecto es muy extensa, como también son infinitas las sentencias en las cuales se utiliza el control de racionalidad/proporcionalidad, obra de la Corte constitucional italiana. También en este caso, entonces, la atención estará limitada a algunos casos ejemplificativos, con la conciencia de la parcialidad que caracteriza cualquier tipo de selección de una casuística tan amplia.

${ }^{41}$ Cfr., por ejemplo, D. U. GaletTA, «Il principio di proporzionalità comunitario e il suo effetto di "spill over" negli ordinamenti nazionali», en Nuove autonomie, 2005, 541 ss. Por lo que se refiere a la noción de spill over, véase la noción de efecto «fontana di Bucket» elaborada por M. Patrono (coord.), Studiando i diritti. Il costituzionalismo sul palcoscenico del mondo dalla Magna Charta ai confini del (nostro) tempo. Lezioni, Torino, 2009, págs. 177 ss.

42 Véase J. Ziller, «La sussidiarietà come principio del diritto amministrativo europeo», en Rivista italiana di diritto pubblico e comunitario, 2006, 294, nt. 12. Para un análisis de derecho comparado, cfr. A. Rinella et al. (a cargo de), Sussidiarietà e ordinamenti costituzionali. Esperienze a confronto, Cedam, Padova, 1999.

43 Cfr. G. Tesauro, Proporzionalità e ragionevolezza nella giurisprudenza comunitaria, Ponencia en la reunión de los tribunales constitucionales de Portugal, España e Italia, Roma 24 de octubre de 2013, en www.cortecostituzionale.it.; sobre este punto véase K. LenAerts - J. A. GutiérrezFons, «To Say What the Law of the EU Is: Methods of Interpretation and the European Court of Justice», 20 Columbia J. Eur. L. 3, 51 (2014).

${ }_{44}$ Cfr., en este sentido, por ejemplo, las sentencias de 8 de abril de 1992, causa C-62/90, Commissione/Germania, Racc. pág. I-2757, punto 23, y 5 de octubre de 1994, causa C-404/92 P, X/ Commissione, Racc. pág. I-4737, punto 18. 
a) La proporcionalidad como parámetro de legitimidad de las medidas adoptadas por los Estados miembros limitativas de las libertades fundamentales

En el leading case en materia de libre circulación de mercancías (Cassis de Dijon), el Tribunal de Justicia de la Unión Europea consideró las restricciones introducidas por la normativa alemana a la libertad de circulación de mercancías (en este caso no podía ser comercializado en Alemania el licor Cassis de Dijon porque no respetaba los requisitos de graduación alcohólica que la ley alemana había puesto como condición para la comercialización de bebidas de tipo Cassis) desproporcionadas y no justificadas por exigencias imperativas de interés públi$\mathrm{Co}^{45}$. Y juicios similares se han desarrollado con referencia a la prohibición de la comercialización de productos equivalentes a la cerveza alemana, siempre con referencia a la graduación alcohólica ${ }^{46}$ y a la pasta de trigo duro, considerando que la ley italiana prohibía, incluso con una sanción, no solo la comercialización sino también la importación de productos denominados «pasta», pero obtenidos de trigo blando ${ }^{47}$.

El Tribunal de Justicia, evaluando las restricciones a las libertades económicas establecidas por el Tratado reconoce sin embargo a los Estados un margen discrecional para establecer un nivel al que estos tratan de garantizar la protección de las libertades allí establecidas y el modo en el cual dicho nivel puede ser alcanzado.

En el caso Apothekenkammer des Saarlandes el Tribunal de Justicia consideró legítimo el régimen de autorización previsto por el legislador alemán con referencia a las medidas que reservan únicamente a los farmacéuticos el derecho de

45 Tribunal de Justicia de la Unión, sent. 20 de febrero de 1979, causa 120/78, Cassis de Dijon, en Raccolta, pág. 649, puntos 13 y 14 de los Considerandos, donde se lee: «13. Como se ha observado con razón por la Comisión, la fijación de los valores-límite en relación con el contenido de alcohol de las bebidas puede servir a la estandarización de los productos puestos en el mercado y de sus designaciones, en aras de una mayor transparencia de las transacciones comerciales y ofertas al público; para esto, no se puede venir a examinar la fijación, impuesta por la ley, de contenido mínimo de alcohol como una garantía esencial de la lealtad de las transacciones comerciales, ya que es fácil de garantizar una información adecuada, haciendo obligatorio indicar el origen y el contenido de alcohol en los envases de productos. 14. De lo que se ha dicho se sigue que los requisitos relativos al contenido mínimo de alcohol de las bebidas alcohólicas no persiguen un objetivo de interés general que puede tomar precedencia sobre la libre circulación de mercancías, lo que constituye uno de los principios fundamentales de la Comunidad».

46 Tribunal de Justicia de la Unión, sent. 12 de marzo de 1987, causa 178/84, Commissione c. Germania, en Raccolta pág. 1227.

47 Tribunal de Justicia de la Unión, sent. 14 de julio de 1988, causa 407/85, Drei Glocken, en Raccolta pág. 4233. Cfr. G. Tesauro, Proporzionalità e ragionevolezza nella giurisprudenza comunitaria, cit. 
dirigir una farmacia, recordando el margen de apreciación de los Estados miembros en materia de organización de los servicios sanitarios ${ }^{48}$.

Por el contrario, con referencia a la libertad de establecimiento y a la libre prestación de servicios, el Tribunal de Justicia consideró medidas excesivas, desproporcionadas al objetivo perseguido, aunque justificadas por motivos imperativos de interés general (como la protección del consumidor y la prevención del fraude y de la incitación de los ciudadanos a un gasto excesivo relacionado al juego), las restricciones a las actividades de juego contempladas en la normativa italiana, dirigidas a impedir actividades criminales y fraudulentas (caso Gambelli) ${ }^{49}$.

Otra decisión resolvió el famoso caso Schmidberger ${ }^{50}$, que fue definido «un caso emblemático, casi de escuela, de la interferencia entre los derechos constitucionalmente tutelados a nivel nacional y aquellos tutelados a nivel

48 Tribunal de Justicia de la Unión, sent. 19 de mayo de 2009, causa C-171/07, Apothekenkammer des Saarlandes., puntos 18 y 19 de los Considerandos, donde se lee que: «18. El derecho comunitario no reduce la competencia de los Estados miembros para organizar sus sistemas de seguridad social y para adoptar, en particular, las disposiciones para la organización de los servicios de salud, como las farmacias. Sin embargo, al ejercer esta facultad, se exige a los Estados miembros respetar el derecho comunitario, en particular, las disposiciones del Tratado relativas a la libre circulación, incluida la libertad de establecimiento. Estas disposiciones prohíben a los Estados miembros establecer o mantener restricciones injustificadas al ejercicio de dicha libertad en el sector sanitario" (véase en este sentido, sent. 16 de mayo 2006, causa C-372/04, Watts, en Raccolta, pág. I-4325, puntos 92 e 146, y sent. 10 de marzo 2009, causa C-169/07, Hartlauer, en Raccolta, punto 29). 19 «Al evaluar el cumplimiento de esta obligación, debe tenerse en cuenta el hecho de que la salud y la vida de las personas ocupan un lugar destacado entre los bienes o intereses protegidos por el Tratado y que corresponde a los Estados miembros para determinar el nivel en el que desean garantizar la protección la salud pública y la forma en que este nivel se ha de lograr. Dado que este nivel puede variar de un Estado miembro a otro, una cierta discrecionalidad debe reconocerse a los Estados miembros» (vèase, en este sentido, sent. 11 de diciembre 2003, causa C-322/01, Deutscher Apothekerverband, en Raccolta, pág. I-14887, punto 103; y sent. 11 de septiembre 2008, causa C-141/07, Commissione/Germania, en Raccolta, pág. I-6935, punto 51, y, también, sent. Hartlauer, cit., punto 30).

49 Tribunal de Justicia de la Unión, sent. 6.de noviembre 2003, causa C-243/01, Gambelli, donde se lee textualmente que «En cuanto a la proporcionalidad de la normativa italiana en materia de libertad de establecimiento, aunque el objetivo de las autoridades de un Estado miembro es evitar el riesgo de que los concesionarios de juegos estén involucrados en actividades delictivas o fraudulentas, la exclusión de la posibilidad de que las empresas de capital cotizadas en mercados regulados de otros Estados miembros puedan conseguir las concesiones de gestión de las apuestas deportivas, sobre todo cuando hay otras maneras de controlar las cuentas y actividades de dichas empresas, puede ser una medida que va más allá de lo necesario para evitar el fraude» (así el punto 74 de los Considerandos).

50 Tribunal de Justicia de la Unión, sent. 12 giugno 2003, causa C 112-00. 
comunitario» ${ }^{51}$, en la cual el Tribunal de Justicia realizó un equilibrio entre las libertades de expresión y de reunión, garantizadas por las ordenanzas austríacas y la libre de circulación de mercancías, asegurada por el Tratado.

En este caso, si bien la libre circulación de bienes representa ciertamente uno de los principios fundamentales del sistema del Tratado, en algunas circunstancias puede sufrir restricciones, como los derechos de libertad de expresión y a la libertad de reunión pacífica, y no aparecen «como prerrogativas absolutas sino que deben ser consideradas a la luz de su función social» ${ }^{52}$. El Tribunal de Justicia debió por lo tanto «verificar si las restricciones impuestas a los cambios intercomunitarios [eran] proporcionadas con referencia al legítimo objetivo perseguido, o sea en este caso la tutela de los derechos fundamentales ${ }^{53}$. A tal fin examinó la intención de los demandantes el ejercicio de los derechos fundamentales y reveló que, en este caso, la «manifestación pública no tenía como objetivo impedir los intercambios de bienes que hubieran tenido una naturaleza o un origen particular» a diferencia del caso que se concluyó con la sentencia Commissione/Francia ${ }^{54}$. En esta causa, de hecho, el objetivo perseguido por los manifestantes era el de «impedir la circulación de determinados productos provenientes de estados miembros diferentes a la república francesa, no solo mediante la oposición de obstáculos al transporte de los bienes en cuestión, sino también mediante la destrucción de los mismos durante la fase de expedición o de tránsito a través de Francia, o incluso cuando estos ya se encontrasen expuestos en las tiendas del Estado miembro interesado» ${ }^{55}$.

\section{b) La proporcionalidad como parámetro de validez de los actos de las instituciones de la Unión Europea: el control de las políticas monetarias del BCE}

El Tribunal de Justicia utiliza además el juicio de proporcionalidad como parámetro de validez de los actos de la Unión. Por ejemplo, en el caso Azienda

51 Cfr. F. Sorrentino, La tutela multilivello dei diritti, en Riv. It. Dir. Pubbl. Com., 2005, págs. 79 ss.

52 Tribunal de Justicia de la Unión, sent. 12 de junio 2003, cit., punto 80.

53 Tribunal de Justicia de la Unión, sent. 12 de junio 2003, cit., punto 81. Sobre la evaluación de proporcionalidad de la intervención restrictiva en materia de derechos, cfr. la sent. 8 de abril 1992, causa C-62/90, Commissione /Germania, en Racc. 1992, pag. I-2757, punto y la sent. 5 de octubre 1994, causa C-404/92, X/Commissione, Racc. 1994, pag. I-4737, punto 18.

54 Tribunal de Justicia de la Unión, sent. 9 de diciembre 1997, causa C-265/95, Commissionel Francia, Racc. 1997, pag. I-6959.

55 Tribunal de Justicia de la Unión, sent. 12 de junio 2003, cit. punto 86. 
Disarò el Tribunal, llamado a verificar la validez de un reglamento del cual se deducía la idoneidad para alcanzar los objetivos de la política agrícola común, se limitó a poner en evidencia que el reglamento «no era manifiestamente inadecuado para la búsqueda del objetivo de la estabilización de los mercados» y que «según el principio de proporcionalidad, no reveló ningún elemento dirigido a afectar la validez del reglamento en cuestión» ${ }^{56}$.

También el caso Monsanto ${ }^{57}$ es emblemático al respecto: el Tribunal de Justicia había sido llamado a pronunciarse sobre el reglamento (n. 258/1997/CE), que permite mediante un procedimiento simplificado, —una simple notificación a la Comisión - la puesta en comercio de alimentos producidos a partir de organismos genéticamente modificados, pero que ya no contienen ninguno, cuando sean sustancialmente equivalentes a los alimentos tradicionales comparables.

$\mathrm{Al}$ controlar el respeto del principio de proporcionalidad de tal procedimiento, el Tribunal de Justicia reafirmó que «con el fin de establecer si una norma de derecho comunitario es conforme al principio de proporcionalidad, se debe comprobar si los medios contemplados por ella son idóneos para alcanzar el objetivo deseado y no exceden lo necesario para lograr dicho propósito» ${ }^{58}$. Por otro lado, «tratándose de un sector donde el legislador comunitario está llamado a llevar a cabo evaluaciones complejas, el control jurisdiccional del ejercicio de su competencia debe limitarse a examinar que este no haya sido afectado por un error manifiesto o desvío de poder o que el legislador no haya ido manifiestamente más allá de los límites de su poder discrecional» ${ }^{59}$.

Por lo tanto, también en este caso, el Tribunal de Justicia confirmó que donde los actos de las instituciones de la Unión Europea sean fruto de evaluaciones complejas, estos actos deben estar sujetos a un limitado grado de escrutinio, pudiendo ser censurados solamente por error manifiesto ${ }^{60}$.

Un caso evidente en el cual el Tribunal limitó el escrutinio de proporcionalidad al error manifiesto y al vicio evidente de la motivación, ha tenido lugar recientemente (Tribunal de Justicia 14 de junio de 2015) en relación al control de las políticas monetarias del BCE.

56 Tribunal de Justicia de la Unión, sent. 14 de mayo 2009, causa C-34/08, Azienda Disarò c. Milka, en Racc., págs. I-4023 ss., puntos 82-83 (cursivas añadidas).

57 Tribunal de Justicia de la Unión, sent. 9 de septiembre 2003, C-236/01, Monsanto.

58 Cfr. el punto 134 de los Considerandos, (cursivas añadidas), la cual se refiere, en particular, en el sector de productos de especialidades farmacéuticas, a la sentencia Generics (UK) e a., cit., punto 66 de los Considerandos.

59 Cfr. el punto 135 de los Considerandos, (cursivas añadidas).

${ }^{60}$ Cfr., también, en el puntos 204, las conclusiones del Abogado General Alber. 
Después de la llamada «crisis del spread» (entre el 2011 y el 2012) el BCE aprobó en agosto de 2012 el llamado programa OMT «Outrigh Monetary Transactions» (Operaciones monetarias definitivas). Tal programa consistía en un plan de compra en el mercado secundario de títulos de Estado para los países que se hubieran adherido a un programa de asistencia financiera del Fondo Europeo de Estabilidad Financiera (FEFS) o del Mecanismo Europeo de Estabilidad (MES). Como explicaba el mismo BCE, se trataba de un programa dirigido específicamente a depurar el mercado de los títulos de Estado de algunos países de la especulación financiera, que, apostando sobre el posible default de aquellos Estados, provocaba un alza del spread excesivo respecto a los parámetros macroeconómicos de los Estados en cuestión. Esta situación no permitía la utilización de los instrumentos ordinarios de política monetaria, y por lo tanto debían ser necesariamente fijados los precios máximos, para permitir al Banco Central que llevara a cabo sus tareas.

Dicho programa fue impugnado por algunas asociaciones alemanas en el Tribunal constitucional alemán, que a su vez planteó la cuestión de la compatibilidad del programa con las reglas del tratado, sosteniendo además, la violación del principio de proporcionalidad.

El Tribunal constitucional alemán, en relación a tal acto instituyó un control según el modelo del llamado «control débil» sobre los actos de las autoridades económicas. Después de recordar que los actos para ser proporcionales deben ser idóneos para alcanzar objetivos legítimos y no deben exceder los límites de lo que es necesario para lograr tales objetivos, hace presente expresamente que el Sistema Europeo de Bancos Centrales (SEBC) está llamado a realizar elecciones de naturaleza técnica y previsiones y evaluaciones complejas, y en consecuencia es necesario reconocerle, en este contexto, un amplio poder discrecional.

El control se desplaza por lo tanto hacia el respeto de las garantías procesales, entre las cuales es esencial el deber de motivación, «que debe hacer aparecer en manera clara e inequívoca el razonamiento seguido por el autor del acto que se trata». A través de la motivación, según el Tribunal de Justicia, debe evaluarse: a) el análisis de la situación que ha habilitado la medida; b) la idoneidad del acto para alcanzar el objetivo; c) que el acto no vaya más allá de lo necesario para lograr el objetivo ${ }^{61}$.

61 A. PISANESCHI, Legittimo secondo la Corte di Giustizia il piano di allentamento monetario (OMT) della BCE. Una decisione importante anche in relazione alla crisi greca, en Federalismi.it., 1/7/2015, n. 13 , espec. págs. 5 ss.; cfr. también ID., Il programma OMT della BCE al vaglio della Corte di Giustizia: considerazioni sulle Conclusioni dell'Avvocato Generale, ivi, 25/2/2014, n. 4. 
Sobre el primer punto, del análisis realizado no se desprende que exista por parte del BCE ningún manifiesto error de evaluación; sobre el segundo punto «el SEBC podía considerar legalmente que un programa como éste, anunciado en dicho comunicado, fuera idóneo para contribuir a los objetivos perseguidos por el SEBC y por lo tanto al mantenimiento de la estabilidad de los precios»; sobre el tercer punto el programa no va manifiestamente más allá de lo necesario, incluso porque el SEBC «ha ponderado diferentes intereses en juego para evitar efectivamente que puedan producirse, en actuación del programa considerado, inconvenientes manifiestamente desproporcionados respecto a los objetivos perseguidos por este último». El control sobre la proporcionalidad, por lo tanto, incluso siguiendo los esquemas clásicos del test de proporcionalidad, se lleva a cabo a través del mero análisis de la existencia de vínculos lógicos de la motivación, mientras que sobre las evaluaciones efectuadas por el BCE - los presupuestos de la situación económica y los efectos del programa- el Tribunal de Justicia se limita a evaluar la no existencia de «manifiestos errores de evaluación» o que el programa no vaya «manifiestamente más allá de lo necesario para alcanzar dichos objetivos» ${ }^{62}$.

Este modelo de control de proporcionalidad sobre las líneas externas de la motivación, aparece coherente, por otro lado, con la tipología de acto que el Tribunal de Justicia estaba llamado a controlar. Si es cierto, de hecho, que el Tratado prevé la posibilidad de controlar los actos de todas las instituciones comunitarias, y por lo tanto también actos de política monetaria, es también verdad que sobre tales actos la jurisdicción no tiene ni los instrumentos para influir ni, en fin, es oportuno que pueda influir.

Es difícil pensar que los actos de política monetaria y, con mayor razón, los actos de emergencia de política monetaria - independientemente de lo que afirma el Tratado sobre su control jurisdiccional — puedan ser sometidos a un penetrante $-y$ por lo tanto eficiente- control jurisdiccional respecto a los fines que ellos persiguen. Los fines son expresión de evaluación económica verdaderamente complejos, así como los efectos, directos o indirectos de tales medidas ${ }^{63}$.

${ }^{62}$ Para una reconstrucción de los modelos de proporcionalidad, cfr., recientemente, E. BINDI, Test di ragionevolezza e tecniche decisorie della Corte costituzionale (a margine della dichiarazione di incostituzionalità della legislazione elettorale), en Ianus.it, 2014, fasc. 10, y las extensas citas de doctrina allí incluidas.

63 A. PISANESCHI, Legittimo secondo la Corte di Giustizia il piano di allentamento monetario (OMT) della BCE, cit., págs. 8-9. Además, ID., Autorità sovranazionali di regolazione finanziaria e diritto costituzionale, en federalismi.it. 23/12/2015, n. 24; ID., Banca centrale europea, vigilanza bancaria e souranità degli Stati, ivi, 17/9/2014, n. 17; F. Donati, Crisi dell'euro, governance economica e democrazia nell'Unione Europea, en Il Diritto dell'Unione europea, 2013, págs. 337 ss.; ID., La crisi dell'euro tra Corti costituzionali e Corte di giustizia, en federalismi.it., 17/9/2014, n. 17. 


\section{TRIBUNAL EUROPEO DE DERECHOS HUMANOS Y JUICIO DE PROPORCIONALIDAD SOBRE EL MARGEN DE APRECIACIÓN DE LOS ESTADOS}

De igual manera que el Tribunal de Justicia y los Tribunales constitucionales nacionales, también el Tribunal Europeo de Derechos Humanos (en adelante TEDH) utiliza con frecuencia el control de proporcionalidad entre las propias técnicas de argumentación, si bien todavía no de modo tan refinado como en las elaboraciones del Tribunal constitucional alemán y el Tribunal de Justicia (que al ordenamiento alemán debe tanto con referencia al control de «proporcionalidad en sentido estricto»). Las diferencias de origen entre los Tribunales y por lo tanto su diversificación estructural y funcional crean, innegablemente, divergencias en los modos de aplicación de las técnicas de argumentación y, en particular, en el recurso del escrutinio de proporcionalidad. Esto no quita que haya analogías en la búsqueda común de instrumentos para evaluar los equilibrios operados por el legislador entre derechos fundamentales, o para medir las interferencias en un derecho fundamental por cuenta de un acto normativo destinado a perseguir un interés público.

Es sabido que el juicio de proporcionalidad del TEDH cambia al variar el acto objeto del control (acto normativo, acto administrativo, sentencia). Con el fin de captar mejor la afinidad entre la línea de argumentación seguida por el Tribunal de Estrasburgo y el control de proporcionalidad efectuado por los otros Tribunales, es necesario concentrar especialmente la atención sobre los casos en los cuales el objeto del control del Tribunal de Estrasburgo sea un acto legislativo.

Además hay una indudable similitud en la línea de argumentación tanto del TEDH como del Tribunal de Justicia, dirigida a reconocer a los Estados un cierto margen de apreciación en relación a las medidas generales con naturaleza legislativa restrictiva de los derechos fundamentales ${ }^{64}$.

${ }^{64}$ Sobre la doctrina del margen de apreciación cfr, ex multis, M. J. GANSHOFF VAN DER MeERsch, Le caractère autonome des termes et la marge d'appréciation des gouvernaments dans l'interprétation de la Convention européenne des droits del'homme, en Melanges Wiarda, Carl Heymans Verlag, 1988, págs. 201 ss.; A. D. Olinga- C. PiCheral, La théorie de la marge d'appréciation dans la jurisprudence récente de la Cour européenne de droits de l'homme, en Revue Trimestrielle des Droits de l'Homme, 1995, núm. 24, págs. 567 ss.; M. Delmas Marty - M. L. Izorche, Marge nationale d'appréciation et internationalisation du droit, en Revue internationale de droit comparé, 2000, págs. 753 ss.; Y. Arai-Takahashi, The Margin of Appreciation Doctrine and the Principle of Proportionality in the Jurisprudence of the ECHR, Antwerp, Intersentia, 2002; J. GARCIA ROCA, El margen de apreciación nacional en la interpretación del Convenio Europeo de Derechos Humanos: soberanía e integración, Cuadernos Civitas, Aranzadi, 2010. 
El margen de apreciación en la jurisprudencia del TEDH determina, de hecho, el espacio asignado a cada Estado en sede de aplicación del Convenio Europeo de Derechos humanos para operar el equilibrio entre las obligaciones de los tratados y la búsqueda de los propios intereses estatales. En el espacio de elección dejado a los Estados, funciona como contrapunto el control del TEDH sobre la legitimidad y, especialmente, sobre la proporcionalidad de las medidas derogatorias a las disposiciones del CEDH. Como es sabido, las condiciones de legitimidad han sido deducidas de las normas del CEDH —en particular de los arts. 8 (derecho al respeto de la vida privada y familiar), 9 (libertad de pensamiento, de conciencia y religión), 10 (libertad de expresión), 11 (libertad de reunión y asociación)_, que prevén expresamente medidas limitantes de los derechos convencionales, como: a) la previsión legal de la medida limitante del derecho, b) el propósito legítimo de la limitación; c) la proporcionalidad de la medida respecto a su objetivo («medida necesaria en una sociedad democrática») ${ }^{65}$.

Es a través del juicio de proporcionalidad como el TEDH logra controlar el margen de apreciación y fijar los márgenes, incluso caso por caso. Y justamente con el fin de no aplicar de manera penetrante el control de proporcionalidad y mantenerse en una posición de self-restraint, el TEDH ha elaborado el criterio del consensus standard, con el objetivo de verificar la legitimidad de las medidas derogatorias, o de las medidas que constituyen una interferencia respecto a las disposiciones del CEDH, adoptadas por los Estados ${ }^{66}$.

En otras palabras, el TEDH comprueba la presencia de un consenso internacional en lo que respecta el nivel de tutela del derecho existente en los diferentes países y lo eleva a standard mínimo de tutela.

Los límites del margen de apreciación tienden, por lo tanto, a ensancharse o a reducirse en relación a la falta o a la existencia del consensus standard. Y esto se refleja invariablemente en el modo de uso del escrutinio de proporcionalidad: más rigurosos si el margen de apreciación nacional es reducido, menos penetrante si el margen es más amplio.

65 Así B. Randazzo (a cargo de), Il sindacato sulla ragionevolezza della legge e lo scrutinio di proporzionalità sul margine di apprezzamento riservato allo Stato in rapporto a misure generali aventi natura legislativa. Aspetti problematici del dialogo tra le Corti, en Corte Constitucional, Departamento de Investigación, I principi di proporzionalità e ragionevolezza nella giurisprudenza costituzionale, anche in rapporto alla giurisprudenza delle corti europee, Cuaderno preparado durante la reunión trilateral entre la Corte constitucional italiana, el Tribunal constitucional español y el Tribunal constitucional portugués, julio 2013, en www.cortecostituzionale.it, pág. 33.

66 K. Dzentsiarou, European Consensus and the Legitimacy of the European Court of Human Rights, Cambridge, 2015, 203; S. Dothan, Why Granting States a Margin of Appreciation Supports the Formation of a Genuine European Consensus, ICourts Working Papers Series, The Danish National Research Foundation's Centre of Excellence for International Courts, 22/2015, págs. 5 ss. 
Solo para dar un ejemplo, el TEDH tiende a la máxima expansión del margen con referencia a cuestiones que conciernen al derecho de propiedad previsto por el artículo 1 del I Protocolo, que admite como cláusulas de interferencia «el interés público» y «el interés general». En la hipótesis en la cual las medidas derogatorias persigan finalidades de política social ${ }^{67}$, el TEDH reconoce un amplio margen de apreciación, limitándose a «un control sobre todo exterior, concentrado en la subsistencia del interés público» (o mejor, sobre su obvia ausencia).

Por otro lado, el ámbito de la propiedad constituye «un típico ejemplo de cómo en una sociedad democrática pueden existir diferentes visiones acerca del equilibrio entre derecho individual e intereses sociales; los redactores del Protocolo, en ausencia de una unívoca noción de derecho de propiedad en Europa, han dejado por lo tanto, una cierta discreción a los Estados contrayentes ${ }^{68}{ }^{2}$ : en este ámbito faltan principios comunes de los Estados, por ejemplo, sobre la legitimidad de la expropiación (el llamado consensus standard).

Después de todo, que el TEDH quiera moverse con prudencia y sea animado por el self-restraint lo demuestra el hecho de que, generalmente, en el momento de evaluar las medidas derogatorias de los derechos convencionales, no tiende a comprobar si pueden existir algunas menos restrictivas, sino que se conforma con verificar que el legislador estatal no haya pasado los límites del margen de apreciación, como por ejemplo en el caso Evans, en el tema de la destrucción de embriones congelados ${ }^{69}$.

El margen de apreciación dejado a los Estados afecta además, como es evidente, a la naturaleza del derecho ejercitado, como resulta de la jurisprudencia en

${ }^{67}$ Cfr., por ejemplo, en el caso Lithgow del 1986, el TEDH desestimó el recurso contra una ley de nacionalización sospecha de conflicto con el artículo 1 del Protocolo debido a la insuficiencia de las compensaciones concedidas, señalando que las autoridades nacionales están en una mejor posición para determinar cuál debe ser la medida más apropiada de «indemnización» (cfr. Sentencia TEDH, 8 de julio de 1986, Lithgow v. Reino Unido, en Rivista di Diritto Internazionale, 1987, pág. 389). En el caso James del 1986, el Tribunal confirma su jurisprudencia sobre el tema de la better position que los Estados mantendrían en la evaluación de interés público, y también sobre el tema de la ausencia de principios comunes de los Estados con respecto a la legalidad de la expropiación (Tribunal Europeo de Derechos Humanos, 21 de febrero de 1986, James y otros v. Reino Unido, 1986, ECHR 2, Series A núm. 98).

68 Así F. Donati- P. Milazzo, La dottrina del margine di apprezzamento nella giurisprudenza della Corte europea dei Diritti dell'Uomo, en Rivista AIC, 2002, págs. 21 e 26.

${ }^{69}$ Cfr. Sentencia TEDH, 7 de marzo 2006 y 10 de abril de 2007, Evans v. Reino Unido, en Revue Trimestraille de Droit Civil., 2007, págs. 190 ss. Véase J. BомноFf - L. ZucCA, The Tragedy of Ms. Evans: Conflicts and Incommensurability of Rights, en European Constitutional Law Review, 2006, 2, 3, págs. 424 ss. 
materia de derecho al respeto de la vida privada o familiar (art. 8) y las modalidades de su ejercicio, como emerge claramente de la jurisprudencia en tema de libertad de expresión del pensamiento (art. $10 \mathrm{CEDH}$ ).

Con referencia al art. 8 , y al derecho al respeto de la vida privada en él tutelado, ha restringido de hecho, notoriamente, el margen de apreciación de los Estados, por ser un valor irrenunciable objetivo e indiscutible, en el cuadro de una sociedad democrática (caso Dudgeon, en el cual el TEDH declaró ilegítima la previsión de una sanción penal para las relaciones homosexuales desarrolladas en privado entre adultos con consentimiento mutuo ${ }^{70}$ ). Y a los efectos de restringir el margen de apreciación, ha tenido presente, en el momento del equilibrio, tres elementos: la definición de sociedad democrática, la importancia atribuida al interés con el cual se interfiere y al objetivo de la interferencia ${ }^{71}$.

La jurisprudencia en materia de libertad de expresión de pensamiento (art. 10 $\mathrm{CEDH}$ ), ha evidenciado además, de qué manera esta libertad es una piedra angular del sistema convencional, derecho ineludible en una sociedad democrática y reductible solo por exigencias excepcionales (caso Sunday Times) ${ }^{72}$. No han faltado, sin embargo, casos en los cuales el TEDH ha acordado una tutela diferente a este derecho, ensanchando o restringiendo el margen de apreciación, según modalidades concretas con las cuales el ejercicio de la libertad de expresión se ha realizado: es suficiente pensar cuán diferente es la libertad de expresar insultos racistas, de la libertad de expresar opiniones de tipo político ${ }^{73}$.

Un terreno indiscutible de elección del control de la razonabilidad-proporcionalidad en la jurisprudencia del TEDH es, finalmente, la aplicación del art. 14 sobre la prohibición de la discriminación.

Como se ha visto, también en la jurisprudencia de la Corte constitucional italiana las primeras aplicaciones del control de razonabilidad han utilizado como parámetro de referencia el principio de igualdad para censurar las leyes que sin un motivo razonable regularan en modo diferente situaciones iguales.

${ }^{70}$ Cfr. Sentencia TEDH, 22 de octubre de 1981, Dugdeon v. Reino Unido, 1981, en ECHR 2, Series A, núm. 45.

${ }^{71}$ Cfr. Sentencia TEDH, 25 de febrero de1997, Z. c. Finland, en http://www.echr.coe.int.

72 Cfr. Sentencia TEDH, 26 de abril de 1976, The Sunday Times v. Reino Unido, 1981, ECHR 2, Series A núm. 20. Vèase, nuevamente, F. Donati- P. Milazzo, op. cit., págs. 21 ss.

73 Cfr. E. Bindi, Dal diritto di punire al dovere di educare, en M. D’Auria-G. Gimigliano-N. VIzIoli, Il Passato, il presente, il futuro. Rileggendo il diritto positivo con metodo storico, Pacini Giuridica, Pisa, págs. 7 ss. 
En el leading-case Belgian linguistic minorities de $1968^{74}$, el TEDH ha elaborado un test de razonabilidad (definido por el mismo Tribunal «razonable relación de proporcionalidad») que corresponde según la tripartición del modelo alemán a un control de adecuación-congruencia de los medios preelegidos respecto al fin perseguido. En este caso, el TEDH de hecho ha articulado la línea de argumentación requerida para comprobar la subsistencia de una discriminación ilegítima en tres pasos: 1) la diferenciación entre sujetos que se encuentran en la misma situación; 2) la carencia de una adecuada y razonable justificación de tales diferencias; 3) la desproporción entre objetivo perseguido y medios utilizados ${ }^{75}$.

Los ejemplos podrían continuar y el excursus jurisprudencial podría enriquecerse sin fin. De todos modos, de esta breve revisión, es posible obtener la línea de fondo seguida por el TEDH sobre el margen de apreciación de los Estados - y sobre el juicio de proporcionalidad como instrumento de control de su uso--: dicha jurisprudencia, elaborada inicialmente con referencia al art. $15 \mathrm{CEDH}^{76}$ y después desarrollada también con referencia a los otros derechos convencionales ${ }^{77}$, es expresión de la búsqueda por parte del TEDH de instrumentos para operar con self-restraint, para respetar el quantum de elecciones discrecionales sobre las medidas derogatorias de los derechos convencionales que corresponden a los Estados. Finalmente, la extrema variedad de casos sobre los cuales deben pronunciarse los jueces de Estrasburgo, la elasticidad de las normas aplicadas, la ductilidad de los instrumentos utilizados, no permiten una reconstrucción unitaria de la doctrina del margen de apreciación nacional ${ }^{78}$. Es decir, el margen no

${ }^{74}$ Cfr. Sentencia TEDH, 23 de julio de 1968, Escuela lingüística belga v. Bélgica, en ECHR, Series A, núm. 6; caso en el que el Tribunal se distanció del origen de la doctrina del margen de apreciación, es decir la situación de emergencia ex art. 15; sobre esta sentencia, cfr. F. R. BARBArosa Delgado, «Los Límites a la Doctrina del Margen Nacional de Apreciación en el Tribunal Europeo y la Corte Interamericana de Derechos Humanos: Intervención Judicial en Torno a Ciertos Derechos de las Minorías Étnicas y Culturales», en Revista Derecho del Estado, 2011, núm. 26.

75 Sobre el punto cfr. también las sentencias del TEDH de 13 de junio de 1979, Marckx $v$. Bélgica, 1981, ECHR 2, Serie A, núm. 31, y de 23 de junio de 1993, Hoffmann v. Austria, 1993, ECHR 2, Serie A, núm. 255 C.

${ }^{76}$ Que permite a los Estados derogar las obligaciones establecidas en el Convenio en caso de guerra o de peligro extremo para la nación.

77 Véase el leading case Handyside (Sentencia TEDH, 7 de diciembre de 1976, Handyside v. Reino Unido, 1975, ECHR 2, Series A núm. 24). Cfr. también Sentencia TEDH, 21 de octubre de 2015, Perinçek v. Suiza, en http://www.echr.coe.int.

${ }^{78}$ Como observan F. Donati- P. Milazzo, op. cit., págs. 27 ss., la imposibilidad de reconstrucción en términos unitarios deriva «de un lado de la naturaleza esencialmente política de determinadas normas convencionales (como el art. $15 \mathrm{CEDH}$ ), y por el otro lado de la estructura diferente de otras disposiciones, que se aplican a menudo en diferentes módulos». Por tanto, estos 
puede ser igual ni en todos los territorios europeos ni tampoco en todos los tiempos, y por eso la doctrina del margen ofrece una cobertura para ponderar realidades sociales muy diversas en el tiempo y en el espacio. «Desde esta óptica sociológica, el margen puede justificar también distintos entendimientos nacionales de los derechos y o únicamente soluciones excepcionales ${ }^{79}$.

La doctrina mayoritaria observa, sin embargo, que el margen no puede concebirse como una «carta blanca» a los Estados para hacer lo que quieran con los derechos de sus justiciables ${ }^{80}$. En definitiva, si el margen comporta un cierto poder discrecional, queda un espacio que escapa a la arbitrariedad de los Estados ${ }^{81}$.

\section{CONSIDERACIONES CONCLUSIVAS}

El principio de proporcionalidad o, mejor dicho, el test de proporcionalidad como técnica argumentativa, nacida en el ordenamiento alemán, ya se ha expandido, gracias al obrar del Tribunal de Justicia entre otras cosas, a muchos países de la Unión Europea. Hasta podría decirse que el principio de proporcionalidad se ha convertido en uno de los conceptos centrales del constitucionalismo global, en calidad de instrumento que favorece el diálogo entre los Tribunales a través de la circulación de modelos jurídicos y standards de argumentación. El modelo alemán no se ha difundido solamente en los países del espacio europeo y en los sistemas de la Unión Europea y del Consejo de Europa, sino que ha logrado

autores subrayan las diferencias de fondo en la doctrina del margen de apreciación en la aplicación del artículo $15 \mathrm{CEDH}$ y en la aplicación de otras disposiciones del Convenio Europeo. En el caso del art. 15 el parámetro que se utiliza para el Tribunal es, sin embargo, por así decirlo, sólo «interno» a la situación en examen, es decir, el Tribunal se limita a evaluar la «necesidad estricta» de la medida adoptada para hacer frente a una situación de emergencia. En otros casos, sin embargo, parece que el parámetro es de alguna manera «externo» de la situación en examen, configurándose como un concepto («medida necesaria en una sociedad democrática») difícil de definir, y desde luego, en cierta medida ligado al concepto de «sociedad democrática» elaborado por los jueces de Estrasburgo».

79 J. Garcia Roca, El margen de apreciación nacional en la interpretación del Convenio Europeo de Derechos Humanos: soberanía e integración, cit., págs. 170-171, que subraya que este argumento se reconduce «a una «interpretación realista o sociológica» que es moneda común en la interpretación jurídica y herramienta habitual en toda jurisprudencia sobre derechos, ya que reclaman una especial comprensión de los hechos e interpretación de las normas mucho más material y anticonformista, menos rigorista, que la diariamente presente en otros sectores del ordenamiento juridíco».

${ }^{80}$ P. Mahoney, Mervellous Richness of Diversity or Invidious Cultural Relativism, en Human Rights Law Journal, vol. 19, 1998, pág. 6.

81 A. D. Olinga- C. Picheral, La théorie de la marge d'appréciation dans la jurisprudence récente de la Cour européenne de droits de l'homme, cit., pág. 603. 
penetrar también en los países del Common law, particularmente en Canadá, para llegar luego a Sudáfrica ${ }^{82}$, Israel y Nueva Zelanda, países que deben mucho al modelo alemán filtrado gracias a la jurisprudencia canadiense ${ }^{83}$. Como es sabido, fue en el famoso caso Oakes en el que la Corte Suprema canadiense elaboró un control de proporcionalidad, basado en el modelo alemán ${ }^{84}$, para verificar si los instrumentos utilizados para limitar un derecho o una libertad estaban reasonable and demostrably justified; y el test de proporcionalidad servía justamente para medir la legitimidad de los objetivos y la proporcionalidad de los medios empleados ${ }^{85}$.

Sin embargo, para que el principio de proporcionalidad se convirtiera en uno de los conceptos centrales del constitucionalismo global, no era suficiente la

82 En particular, se debe enfatizar que el art. 36 de la Constitución de Sudáfrica codifica un test de admisibilidad de las limitaciones de los derechos muy similar a la estructura del test de proporcionalidad, sin mencionar expresamente la palabra «proporcionalidad».

${ }^{83}$ Cfr. T. GroppI, «User-friendly Court. The influence of Supreme Court of Canada Decisions Since 1982 on Court Decisions in Other Liberal Democracies», en Supreme Court Law Review, 2007, págs. 337 ss., que hace hincapié en que la jurisprudencia canadiense puede proporcionar un puente entre la tradición británica de la supremacía del parlamento y el nuevo «Estado constitucional», demostrando que son dos opciones que no son irreconciliables.

${ }^{84}$ Corte Suprema de Canadá, 28 de febrero de 1986, Regina v. Oakes: en el primer caso que formula el test, la Corte Suprema distingue la idoneidad («la medida adoptada debe estar cuidadosamente diseñada para alcanzar el objetivo», punto 139) de la legitimidad del fin («de importancia suficiente como para justificar pasar por encima de un derecho constitucionalmente protegido», punto 138): así I. CovarRubias Cuevas, «La desproporción del test de proporcionalidad: aspectos problemáticos en su formulación y aplicación», en Revista Chilena de Derecho, 2012, vol. 39, n. 2, págs. 447 ss.; cfr., también D. Grimm, «Proportionality in Canadian and German Constitutional Jurisprudence», en University of Toronto Law Journal, 2007, vol. 57, 2, págs. 383 ss; D. Schneiderman - K. Sutherland, Charting the Consequences: the Impact of Charter Rights on Canadian Law and Politics, University of Toronto Press, Toronto, 1997; R. SHARPE, «La Carta canadese dei diritti e delle libertà», en Quaderni costituzionali, 1992, págs. 364 ss.; L. LANZONI, «Problemi e tecniche della sospensione dei diritti fondamentali in prospettiva comparata. Recenti tendenze», en Dir. pubbl. comp. eur., 2005, págs. 1083 ss; F. Rosa, Limiti ai diritti e clausole orizzontali: Canada, Nuova Zelanda, Israele e Sudafrica a confronto, cit.

${ }^{85}$ De manera más precisa, el Chief Justice Dickson, redactor de la decisión Oakes, subraya que para restringir legítimamente el derecho se deben cumplir dos «criterios básicos»: el primero requiere que «el objetivo perseguido debe ser suficientemente importante como para justificar anulando un derecho o libertad protegido por la Constitución»; el segundo establece que «la parte que invoca el artículo 1 debe mostrar que las medidas elegidas sean razonables y claramente justificadas» (cfr. el punto 69). Véase G. Telese, Le limitazioni al godimento di diritti fondamentali secondo i principi generali elaborati dalla Corte suprema del Canada, en G. Rolla (a cargo de), Lo sviluppo dei diritti in Canada. Tra universalità e diversità culturale, Giuffrè, Milano, 2000, págs. 83 ss., espec.101, que hace hincapié en que la jurisprudencia posterior al que ha sido definido como «el legado Dickson» es muy cuidadosa para analizar los tres componentes de la prueba de proporcionalidad: rational connection, minimal impairment e proporzionate effect. 
difusión de las técnicas de decisión por parte de los Tribunales constitucionales y supranacionales, era preciso contar con el apoyo de una base teórica: y a partir de los años ochenta se desarrolló una amplia literatura sobre el tema, a la cual contribuyó sin dudas la doctrina jurídica internacional, en primer lugar con las obras de Robert Alexy, David Beatty y Aharon Barak ${ }^{86}$.

La doctrina europea, a decir verdad, se había concentrado, como hemos visto, en la reconstrucción de las fases del control de racionalidad/proporcionalidad y en la relación entre el test de proporcionalidad y las técnicas de equilibrio, con la finalidad de elaborar standards de juicio como instrumento de control y legitimidad de lo actuado por los Tribunales constitucionales, preocupada por el alto nivel de discrecionalidad que acompaña a la utilización de estos instrumentos decisorios. Los estudiosos europeos eran conscientes de que era inevitable un recurso al control de racionalidad/proporcionalidad por parte de los Tribunales nacionales y supranacionales cuando deben juzgar sobre presuntas violaciones de los derechos, los cuales no solo están formulados por principios, de tipo abierto y heterogéneo, sino que además su multiplicidad hace que sea inevitable el uso de técnicas del equilibrio y su limitación recíproca.

El debate teórico internacional más reciente, si bien ha estado motivado por la misma preocupación, más que concentrarse en invocar una elaboración de standards que contengan la actuación de los jueces, ha llamado la atención sobre los peligros inherentes al escrutinio de proporcionalidad y más en general sobre las técnicas argumentativas de equilibrio. El temor que subyace es que el principio de proporcionalidad, instrumento por excelencia del age of balancing termine sofocando la autonomía de la política democrática ${ }^{87}$.

${ }^{86}$ Entre las obras doctrinales más significativas, cfr. respectivamente R. Alexy, Teoria dei diritti fondamentali (1986), Bologna, il Mulino, 2012; D. BEATTY, The Ultimate Rule of Law, Oxford, Oxford U. P., 2004, 162; A. BARaK, Proportionality. Constitutional Rights and their Limitations, 2010, Cambridge, Cambridge U. P., 2012, cap. 7., referenciados por G. PINO, Proporzionalità, diritti, democrazia, cit.; ID., «Diritti fondamentali e principio di proporzionalità», en Ragion pratica, 2014. Además, cfr. A. Stone Sweet, J. Matthews, «Proportionality Balancing and Global Constitutionalism», en Columbia Journal of Transnational Law, vol. 47, 2008, págs. 73 ss., espec. pág. 80; M. Cohen-Eliya, I. Porat, Proportionality and Constitutional Culture, Cambridge, Cambridge U. P., 2013, cap. 1. L. Prieto Sanchís, «El constitucionalismo de los derechos», en Revista Española de Derecho Constitucional, 2004, 47-72; K. MöLler, The Global Model of Constitutional Rights, Oxford, Oxford U. P., 2012; B. Celano, I diritti nello Stato costituzionale, Bologna, Il Mulino, 2013, caps. 3 y 4.

${ }^{87}$ Sobre este tipo de critica a la utilización de la técnicas de equilibrio y del test de proporcionalidad, L. Ferrajoli, La democrazia attraverso i diritti, Laterza, Roma-Bari, 2013, págs. 121 ss. Además cfr. M. B. Nimmer, «The Right to Speak from Times to Time. First Amendment Theory Applied to Libel and Misapplied to Privacy», en California Law Review, vol. 56, 1968, pág. 947; L. B. Franz, «The First Amendement in the Balance», en The Yale Law Journal, vol. 71, 
Vuelven a emerger sospechas contra los Tribunales, órganos sin legitimidad popular, que sin embargo tienen el poder de invalidar las leyes del Parlamento. En su momento Palmiro Togliatti, miembro del partido comunista italiano, en la Asamblea Constituyente definió la Corte constitucional italiana como una extravagancia, preguntándose «¿de dónde les llega el poder» a estos jueces «si el pueblo no ha sido llamado a elegirlos?» ${ }^{88}$. Y también en los últimos tiempos, en un clima candente desencadenado por la declaración de ilegitimidad constitucional de la ley que suspendía los procedimientos penales de los máximos representantes del Estado ${ }^{89}$, el ministro de justicia Alfano ha recordado las palabras pronunciadas por Togliatti para reprochar a la Corte un uso instrumental de las declaraciones de inconstitucionalidad con el fin de perseguir finalidades políticas contra las decisiones tomadas por los órganos que fundan su poder en la soberanía popular.

Más de dos siglos de constitucionalismo ya deberían haber demostrado ampliamente que el problema de la falta de legitimación democrática de los Tribunales constitucionales es un problema mal planteado, resultado de malentendidos sobre el funcionamiento de los mecanismos democráticos. Como es sabido, en las democracias contemporáneas, las elecciones de la mayoría prevalecen sobre las reivindicaciones de la minoría, que de todos modos aceptan las decisiones mayoritarias no porque la decisión de la mayoría sea intrínsecamente justa, sino porque se trata de una decisión basada en valores compartidos; por ello, la minoría, aun estando subordinada a las elecciones de la mayoría, resiste a la «tiranía» de esta última gracias a elementos de garantía constitucional con los que cuenta, como el control de constitucionalidad de las leyes.

núm. 81962, págs. 1424 ss; B. Neuborne, «Notes for a Theory of Constrained Balancing in First Amendment Cases: An Essay in Honor of Tom Emerson», en Case Western Law Review, vol. 38, 1988, 578; P. DE LORA, «Tras el rastro de la ponderación», en Revista Española de Derecho Constitucional, 2000, núm. 60, pág. 367 (comentario al libro de J. M. Rodríguez DE SANTIAGO, La ponderación de bienes e intereses en el Derecho administrativo, Marcial Pons, Madrid, 2000); L. PalomBELla, The Rule of Law as an Institutional Ideal, en L. MoRlino - L. PALOMbella (a cargo de), Rule of Law and Democracy. Inquiries into Internal and External Issues, Leiden, 2010, págs. 32 ss.

${ }^{88}$ Cfr. P. Togliatti, sesión de la tarde del 11 marzo 1947, en La Costituzione della Repubblica nei lavori preparatori dell'Assemblea Costituente, a cargo de la Secretaría General de la Cámara de Diputados, Roma 1970, vol. I, págs. 330 ss. Como es sabido, las fuerzas de izquierda temían, en particular, la introducción de controles sobre las leyes del Parlamento, fuerzas tal vez conscientes de los obstáculos que se opusieron por la Corte Suprema de los Estados Unidos de América a las políticas de intervención social decididas por el presidente Roosevelt en el primer período del New Deal.

${ }^{89}$ Cfr. la sentencia de la Corte constitucional italiana sobre el «lodo Alfano» (sent. n. 262 del 2009, en Giur. cost. 2009, págs. 3645 ss.). 
La existencia de un órgano de garantía, llamado a controlar y, llegado el caso, a corregir la decisión de la mayoría, constituye una herramienta irrenunciable de tutela de los valores fundamentales del ordenamiento, ya sea interno o supranacional. Los Tribunales constitucionales hallan el fundamento de su legitimidad democrática no en la elección popular, sino en la función llevada a cabo, gracias a la cual las minorías aceptan las decisiones mayoritarias, en los casos y como expresión de valores compartidos.

Claramente, existe siempre la posibilidad de que, para contener la tiranía de la mayoría, se abra una puerta a la tiranía de los órganos de garantía; es innegable que la aplicación de derechos con una formulación tan amplia y el consiguiente recurso a técnicas de equilibrio puede cambiar el eje del poder de decisión de los órganos representativos, titulares de la dirección política hacia los órganos no representativos, de garantía. Y es para afrontar dicha eventualidad para lo que la doctrina de la zona europea a través de los años ha elaborado técnicas de decisión, como tests de proporcionalidad, a modo de control de las distintas motivaciones elaboradas por los Tribunales, de modo que las decisiones no las pongan al resguardo de las críticas ${ }^{90}$.

Para concluir, utilizar los tests de proporcionalidad permite controlar que las decisiones de la mayoría no perjudiquen los derechos individuales; sin embargo, si bien los Tribunales elaboran tests y los aplican coherentemente, haciéndolo de manera que a ellos correspondan procedimientos argumentativos bien determinados, de los cuales deriva un mejor control sobre las motivaciones, no por esto los peligros de arbitrariedad de los Tribunales, en la evaluación del equilibrio llevado a cabo por el legislador, están contenidos ${ }^{91}$. Los Tribunales conservan siempre el poder de individualizar el punto de equilibrio entre los derechos en conflicto y subvertir la decisión del órgano representativo o hasta la afirmación de que el núcleo esencial de un derecho debe ser preservado, no es suficiente para

90 Sobre la importancia de la motivación como la herramienta de control de la argumentación seguida por la Corte constitucional italiana cuando se emplea el criterio de racionabilidad véase R. Romboli, Il significato essenziale della motivazione per le decisioni della Corte costituzionale in tema di diritti di libertà pronunciate a seguito di bilanciamento tra valori costituzionali contrapposti, en V. Angiolini (a cargo de), Libertà e giurisprudenza costituzionale, Torino, Giappichelli, 1992, págs. 206 ss.

${ }_{91}$ Problema este, por lo demás, bien presente para el relator de la sentencia de la Corte costituzionale italiana, núm. 1130 de 1988, cit. En efecto, este último, algunos años atrás, y en otra sede, no sin ironía había observado: «y ¿qué es la razonabilidad si no [...] lo que quince hombres (o incluso menos) reunidos en el Palacio de la Consulta consideran según su arbitrio que es razonable?»: así A. BALDASSARre, Intervento, en N. Occhiocupo (a cargo de), La Corte costituzionale tra norma giuridica e realtà sociale, Bologna, 1978, pág. 127. 
contener el amplio poder discrecional de los Tribunales y no logra disipar los temores de su posible abuso.

No obstante los innegables riesgos de que los Tribunales puedan llegar a un zona prohibida para ellos, subvirtiendo el delicado equilibrio de las decisiones de los órganos representativos en el tema de los derechos fundamentales, y a pesar de las inevitables grietas que se podrían verificar por este motivo en el modelo de judicial review si los tribunales constitucionales abusaran de sus poderes, el control de legitimidad sobre los actos legislativos por parte de órganos «neutros o terceros» constituye sin duda un instrumento imprescindible no solo de incremento del buen funcionamiento democrático de los Estados constitucionales, sino de la subsistencia misma de dicho funcionamiento en las democracias contemporáneas.

Title:

Proportionality test in the «Age of balancing»

\section{Summary:}

1. PREFACE. 2. LEVELS OF BALANCE. 3. EQUALITY AND REASONABLENESS. 4. PROPORTIONALITY IN THE GERMAN MODEL. 5. PROPORTIONALITY IN THE EUROPEAN COURT OF JUSTICE: a) Proportionality as legitimacy parameter of measures restricting fundamental freedoms. b) Proportionality as validity parameter of acts of the European institutions: the monitoring on the monetary policies. 6. EUROPEAN COURT OF HUMAN RIGHTS AND EVALUATING PROPORTIONALITY: THE MARGIN OF APPRECIATION FOR EU MEMBER STATES. 7. FINAL CONSIDERATIONS.

\section{Resumen:}

El estudio analiza el principio de proporcionalidad, o mejor dicho el test de proporcionalidad como técnica argumentativa aplicada por la Corte constitucional italiana, por el Tribunal de Justicia y por el Tribunal Europeo de Derechos Humanos. Esta técnica argumentativa, nacida en el ordenamiento alemán, ya se ha expandido, gracias al obrar del Tribunal de Justicia entre otras cosas, a muchos países no solo de la Unión Europea, sino también de common law. Hasta podría decirse que el principio de proporcionalidad se ha convertido en uno 
de los conceptos centrales del constitucionalismo global, en calidad de instrumento que favorece el diálogo entre los Tribunales a través de la circulación de modelos jurídicos y standards de argumentación.

Después una premisa sobre las constituciones de la segunda posguerra en la Europa occidental, en la que se enuncian más que nada principios, caracterizados por circunstancias abiertas y heterogéneas, se tratan por separado las técnicas de equilibrio elaboradas por el legislador y también por el juez ordinario. El estudio prosigue señalando la existencia de diversos precedentes, prestando atención especial a la sentencia n. ${ }^{\circ} 1$ del 2014 de la Corte constitucional italiana, que declaró incostitucional la ley electoral n. ${ }^{\circ} 270$ de 2005 para la elección del Parlamento italiano y a la sentencia del Tribunal de Justicia (14 de junio de 2015) en materia de control de las políticas monetarias del BCE.

Para terminar, se tiene en cuenta la doctrina europea y de países del common law, que expresa su preocupación por el alto nivel de discrecionalidad que acompaña a la utilización de estos instrumentos decisorios. El debate teórico internacional más reciente se centró en el déficit de legitimación democrática de los Tribunales constitucionales y llamó la atención sobre los peligros inherentes al escrutinio de proporcionalidad y más en general sobre las técnicas argumentativas de equilibrio. El temor que subyace es que el principio de proporcionali$\mathrm{dad}$, instrumento por excelencia del age of balancing termine sofocando la autonomía de la política democrática.

A pesar de los innegables riesgos inherentes a las operaciones de control efectuadas por los Tribunales constitucionales sobre las decisiones de los órganos representativos, el estudio acepta la tesis de la doctrina según la cual la existencia de un órgano de garantía, llamado a controlar y, llegado el caso, a corregir la decisión de la mayoría, constituye una herramienta irrenunciable de tutela de los valores fundamentales del ordenamiento, ya sea interno o supranacional. Los Tribunales constitucionales hallan el fundamento de su legitimidad democrática no en la elección popular, sino en la función llevada a cabo, gracias a la cual las las minorías aceptan las decisiones mayoritarias, en los casos y como expresión de valores compartidos.

\begin{abstract}
:
The article analyzes the application of the principle of proportionality, or rather of the proportionality test as interpretative criterion of the Italian Constitutional Court, European Court of Justice and European Court of Human Rights. This criterion was originally adopted within the German legal order and then, thanks to the jurisprudence of the European Court of Justice, it has spread in many countries including common law countries. Therefore, the proportionality
\end{abstract}


test became one of the central concepts of global constitutionalism, as an instrument fostering the dialogue between the courts through the circulation of legal models and argumentative standards.

The paper starts with an introduction relating to the development of European constitutions from the end of World War II up to now and containing mostly principles that are characterized by open and heterogeneous cases. Then, the paper analyzes the techniques of balance that are particularly used both in new legislation and case-law.

The analysis continues with an examination of the case study, with special attention to Sentence n. 1 of 2014 of the Italian Constitutional Court (which declared the unconstitutionality of the electoral system for the election of Parliament) and the Decision of the European Court of Justice of 14 June 2015 relating to the assessment of the ECB's monetary policy.

Finally, this paper examines European and non EU doctrine that has shown its main concern due to the wide discretion that these decision-making instruments allow. In fact, the most recent international theoretical debate has focused on the deficit of democratic legitimacy occurring in the jurisprudence of constitutional courts and has drawn the attention to the inherent danger in the scrutiny of proportionality and, more generally, in all the interpretative techniques of balance. The above-mentioned fear involves the fact that the principle of proportionality, which is the «par excellence» instrument of the «AGE of balancing», ends up stifling the democratic political autonomy.

Despite the undeniable risk that courts can go into a non-allowed land, subverting the delicate balance of the decisions of the representative bodies, this paper accepts the idea that the existence of an oversight body, aimed at criticizing and, when appropriate, correcting the majority decision, is an indispensable instrument to protect the fundamental values both of national and international legal orders.

In short, constitutional courts do not find the basis of their democratic legitimacy in popular election, but in their function itself, so as that the majority decision is also accepted by the minority forces if and to the extent it is the expression of shared values.

\section{Palabras clave:}

test de proporcionalidad, Corte constitucional italiana, TJUE, TEDH, constitucionalismo global, equilibrio, age of balancing.

\section{Key words:}

Proportionality test, Italian Constitutional Court, ECJ, ECHR, global constitutionalism, levels of balance, age of balancing. 
